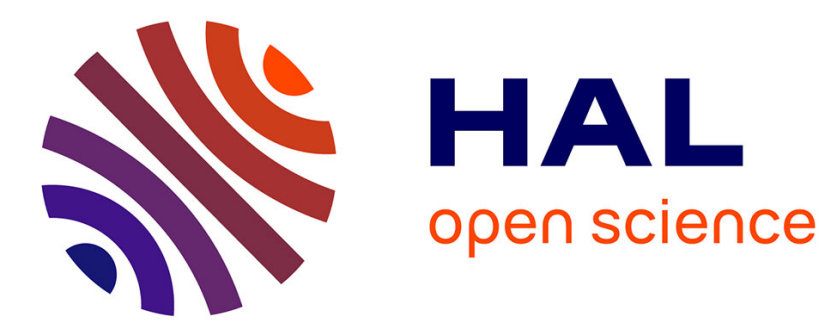

\title{
Large discrepancies in summer climate change over Europe as projected by global and regional climate models: causes and consequences
}

\author{
Julien Boe, Samuel Somot, Lola Corre, Pierre Nabat
}

\section{To cite this version:}

Julien Boe, Samuel Somot, Lola Corre, Pierre Nabat. Large discrepancies in summer climate change over Europe as projected by global and regional climate models: causes and consequences. Climate Dynamics, 2020, 54 (5-6), pp.2981-3002. 10.1007/s00382-020-05153-1 . hal-02908731

\section{HAL Id: hal-02908731 \\ https://hal.science/hal-02908731}

Submitted on 9 Nov 2020

HAL is a multi-disciplinary open access archive for the deposit and dissemination of scientific research documents, whether they are published or not. The documents may come from teaching and research institutions in France or abroad, or from public or private research centers.
L'archive ouverte pluridisciplinaire HAL, est destinée au dépôt et à la diffusion de documents scientifiques de niveau recherche, publiés ou non, émanant des établissements d'enseignement et de recherche français ou étrangers, des laboratoires publics ou privés. 


\title{
Large discrepancies in summer climate change over Europe as projected by global and regional climate models : causes and consequences
}

\author{
Julien Boé · Samuel Somot • Lola \\ Corre · Pierre Nabat \\ Received : date / Accepted : date
}

8 Résumé We assess the differences of future climate changes over Europe in summer as projected by state-of-the-art regional climate models (RCM, from 10 the EURO-Coordinated Regional Downscaling Experiment) and by their for1 cing global climate models (GCM, from the Coupled Model Intercomparison 12 Project Phase 5) and study the associated physical mechanisms. We show that important discrepancies at large-scales exist between global and regional projections. The RCMs project at the end of the 21st century over a large area of Europe a summer warming 1.5-2 K colder, and a much smaller de${ }_{16}$ crease of precipitation of $5 \%$, versus $20 \%$ in their driving GCMs. The RCMs 17 generally simulate a much smaller increase in shortwave radiation at surface, 18 which directly impacts surface temperature. In addition to differences in cloud cover changes, the absence of time-varying anthropogenic aerosols in most regional simulations plays a major role in the differences of solar radiation changes. We confirm this result with twin regional simulations with and without time-varying anthropogenic aerosols. Additionally, the RCMs simulate larger increases in evapotranspiration over the Mediterranean sea and larger increases / smaller decreases over land, which contribute to smaller changes in relative humidity, with likely impacts on clouds and precipitation changes. Several potential causes of these differences in evapotranspiration changes are discussed. Overall, this work suggests that the current EURO-CORDEX RCM ensemble does not capture the upper part of the climate change uncertainty

J. Boé

CECI, Université de Toulouse, CERFACS / CNRS, Toulouse

E-mail: boe@cerfacs.fr

S. Somot

CNRM, METEO-FRANCE / CNRS, Toulouse

L. Corre

DCSC, METEO-FRANCE, Toulouse

P. Nabat

CNRM, METEO-FRANCE / CNRS, Toulouse 
range, with important implications for impact studies and the adaptation policies that they inform.

Keywords Climate change $\cdot$ regional climate $\cdot$ Europe $\cdot$ anthropogenic aerosols $\cdot$ evapotranspiration

\section{Introduction}

The resolution of global climate models (GCMs) is generally too coarse to capture the fine-scale features of the regional climate and key physical processes. This may be problematic to study regional climate phenomena, small regions (islands, mountains) or for the precise assessment of the impacts of climate change. Regional Climate Models (RCMs) are therefore frequently used to downscale low-resolution GCMs in order to obtain the necessary high resolution climate information.

The added value of RCMs compared to GCMs is clear for some aspects of the simulated climate. Variables that strongly depend on orography or that are impacted by land sea contrast benefit of a finer representation of the relief or of the coastline. For example, several studies have highlighted the added value of RCMs for climatological precipitation in mountain regions (e.g. Prein et al. 2016), for extreme precipitation (Déqué et Somot, 2008; Fantini et al., 2018) and for extreme winds (Herrmann et al. 2010).

The added value of RCMs may not be limited to the scales not resolved by GCMs and to the regions of strong physiographic features. Sorland et al. (2018) show a reduction of climatological temperature biases over Europe in two RCMs compared to the multiple GCMs used to force them, not limited to the regions with steep orography or near the coast. They also show important differences in the response to climate change, with a substantially smaller warming in the RCMs, especially over eastern Europe.

While it is in general easy to assess whether RCMs provide a more or a less realistic representation of the present-day climate compared to GCMs, it is obviously much more complicated in the climate change context, as no observational reference then exists. The added value of RCMs for climate change signals is therefore more elusive. Fernandez et al. (2018) based on a very large meta-ensemble of regional and global climate projections have concluded that the projected changes by RCMs and GCMs are essentially similar over Spain. Little added value of RCMs therefore exists in this case, which is not necessarily surprising as we do not necessarily expect an added value at large scales. Conversely, there are also some evidences that physically meaningful differences between RCMs and GCMs may exist in the climate change context, with an added value of RCMs, for example regarding changes in convective rainfall in the Alps in summer (Giorgi et al. 2016).

When differences between projected changes from RCMs and GCMs arise, it should not be automatically concluded that it demonstrates an "added value" of RCMs. The realism of climate projections is much more than a simple 
question of resolution. The physics of the model, the quality of the parameterizations are crucial. It is all the more so true since the same classes of process have to be parameterized in GCMs and RCMs at current standard resolutions. Additionally, some specific methodological issues may exist for RCMs. Some methodological choices such as the use or not of spectral nudging (Colin et al. 2010), the placement of the domain (Leduc et al. 2009) may impact the results in a non negligible way (Giorgi and Gutowski 2015). The lack of coupling with the ocean in most regional climate simulations (Somot et al. 2008; Gaertner et al. 2018, Akhtar et al. 2018) or the potential inconsistencies between the physical parameterizations of the RCMs and its forcing GCMs (Saini et al. 2015, Pinto et al. 2018) may also have some impacts.

Additionally, some climate forcings may be missing in current RCMs. Jerez et al. (2018) mention that some RCMs do not include time-varying $\mathrm{CO}_{2}$ concentrations within the regional domain, affecting the regional change in radiative forcing. They show that, not surprisingly, it impacts temperature changes. Given the importance of the direct and local impact of $\mathrm{CO}_{2}$ on precipitation changes, including over the Mediterranean and Europe (He and Soden 2017) it could also lead to an underestimation of summer drying. It is also deducible from Table 2 in Bartok et al. (2017) and from the table in Annex in Gutierrez-Escribano (in revision) that time-varying concentrations of anthropogenic aerosols are not taken into account by most of the EUROCoordinated Regional Climate Downscaling Experiment (EURO CORDEX, Jacob et al. 2014) RCMs. It could be problematic : Nabat et al. (2014) show with a regional climate model that anthropogenic aerosols explain roughly $81 \%$ of the brightening and $23 \%$ on the surface warming over Europe for the 1980-2012 period. Nabat et al. (2015) also demonstrate the climate impacts of forgetting aerosol mean forcing on radiation, temperature and the water cycle. The inter-model differences in the sensitivity to anthropogenic aerosols also have important impacts in terms of past and future hydrological changes over western Europe (Boé 2016).

It is crucial to assess whether the results of ensembles of regional and global climate projections are consistent, especially at the larger scales resolved by both systems. Should some differences arise, understanding the mechanisms at play is necessary. Only a fine understanding of these mechanisms may allow to conclude whether the RCM or GCM results are more credible, by judging how structural differences between GCMs and RCMs may impact these mechanisms. e.g. Is there a reason to think that the representation of these mechanisms benefits from a higher resolution? Is there any specificity in the regional modelling framework (e.g. lack of ocean-atmosphere coupling) that could be problematic in that context? Are there forcings not taken into account by the RCMs that could be important?

Over most of Europe except Scandinavia, the most preoccupying impacts of climate change are arguably expected to occur during summer, with a decrease in precipitation, very strong over the south of Europe, and an amplified warming (Terray and Boé 2013, Collins et al. 2013, Kröner et al. 2017, Brogli et al. 2019), with associated increases in droughts (e.g. Orlowsky and Sene- 
viratne 2013, Ruosteenoja et al. 2018) and heatwaves frequency and severity (e.g. Fischer and Schär 2010, Schoetter et al. 2015). Additionally, the model uncertainties are also very large in summer over western and central Europe (e.g. Terray and Boé 2013). The first objective of this study is to characterize precisely the differences in projected summer climate changes over Europe between current GCMs and RCMs, from the Coupled Model Intercomparison Project phase 5 (CMIP5, Taylor et al., 2012) and EURO-CORDEX respectively. The second objective is to understand the causes of the differences, in order to better judge of the relative realism of regional and global projections.

In section 2, the data used in this study is described. In the third section, the differences between RCMs and GCMs for precipitation and temperature changes are characterized. In section 4, the role of anthropogenic aerosols in these differences is studied. We analyse the role of the differences in evapotranspiration changes over land in section 5 and over the Mediterranean sea in section 6 . The main conclusions of this study are finally drawn in the last section.

\section{Data and methods}

\subsection{Global and regional climate projections}

In this paper, we study the $12 \mathrm{~km}$ EURO-CORDEX climate projections (Jacob et al. 2014) with most of the variables necessary for our analyses available on the Earth System Grid Fundation (ESGF) at the time of this study. We focus on the highest resolution EURO-CORDEX projections $(12 \mathrm{~km})$ because if the resolution matters, its impact is likely to be greater at $12 \mathrm{~km}$ than at $50 \mathrm{~km}$. A resolution of $12 \mathrm{~km}$ is moreover closer to the needs of most impact studies. We focus on historical and RCP8.5 simulations. The summer changes between the 2070-2099 and 1970-1999 periods are studied. Seven RCMs (some of them in multiple versions) forced by six GCMs from the CMIP5 project, for a total of 24 projections, are analyzed (Table 1). One member per RCMs is studied, as most of the RCMs have a single member.

Some studies have rejected a priori the results of IPSL-WRF331F model after sanity checks, e.g Giorgi et al. (2016) or Rajczak and Schär (2017). We still study this model as it has been used in many previous studies, but we are careful that none of our conclusions depends on whether it is included or not.

An issue has been detected for some regional historical regional simulations forced by CNRM-CM5 (CNRM ALADIN53, CLMcom CCLM4-8-17, SMHI RA4). The historical member of CNRM-CM5 used to provide the lateral boundary conditions is not the same as the one used for the surface forcing. At climatological time scales, which we are interested in, as the two members come from the exact same GCM, this issue is not expected to have important impacts. We therefore use these three RCMs forced by CNRMCM5 in this study. For the other regional simulations forced by CNRMCM5 (CNRM ALADIN63, KNMI RACMO22E, DMI HIRHAM5), this issue 
has been corrected. Some other issues have been noted for EURO-CORDEX RCMs. They are listed in the EURO-CORDEX errata table at https ://eurocordex.net/078730/index.php.en.

The results of the RCMs are compared to the ones of their driving GCMs (Table 1), from the Coupled Model Intercomparison Project Phase 5 (CMIP5, Taylor et al. 2012). In general, the GCM member used to force the RCM is considered. Aside from the issue mentioned above regarding some simulations forced by CNRM-CM5, the only exception concerns the DMI-HIRHAM5 run forced by EC-EARTH. The third members of EC-EARTH was used to provide the boundary forcing to HIRHAM5, but we have not been able to find the output of this member on ESGF. The member 12 of EC-EARTH is used in our analyses as a replacement.

We also characterize the change in precipitation and temperature in a larger ensemble of 37 CMIP5 GCMs (Table 2) to assess whether the smaller ensemble used to drive the EURO-CORDEX RCMs is representative of the full one. To study the role of anthropogenic aerosols, we use 16 CMIP5 GCMs that provide both the aerosols optical depth (AOD) at $550 \mathrm{~nm}$ and clear sky shortwave radiation at surface (Table 2).

Among the RCMs studied, only ALADIN and RACMO use time-varying anthropogenic aerosol forcing. ALADIN uses the same aerosol forcing dataset as its driving GCMs and RACMO uses the aerosol forcing of EC-EARTH independently of its driving GCMs (see the annex of Gutierrez-Escribano et al., in review, for a detailed description of how aerosols aerosols are dealt with in the EURO-CORDEX RCMs). All the forcing GCMs (and more generally all the CMIP5 GCMs) use time-varying anthropogenic aerosol forcing, following the historical and RCP8.5 scenario. The concentrations are prescribed in CNRM-CM5, IPSL-CM5A-MR, EC-EARTH, MPI-ESM-LR and calculated interactively given the concentrations of forcing agents in HadGEM2-ES and NorESM1-M (Table 12.1 in Collins et al. 2013). With respect to the indirect effects of aerosols, HadGEM2-ES and NorESM1-M simulate both the cloud albedo and cloud lifetime effects, CNRM-CM5 and IPSL-CM5A-MR simulate the cloud albedo effect, EC-EARTH and MPI-ESM-LR simulate none of the indirect effects (Table 12.1 in Collins et al. 2013).

WRF331F and HIRHAM5 also do not take into account the time variations of $\mathrm{CO}_{2}$, which, not surprisingly, impacts their results (Jerez et al., 2018).

Among the driving GCMs, EC-EARTH, IPSL-CM5A-MR, HADGEM2ES, MPI-ESM-MR take into account the physiological impact of $\mathrm{CO}_{2}$ on evapotranspiration through the modification of the stomatal resistance (Table 12.1 in Collins et al. 2013). To the best of our knowledge, no RCM studied here simulates this effect. Some other forcings may differ between RCMs and GCMs. Most notably, to the best of our knowledge, the RCMs used in this study do not consider land use / land cover changes. Conversely, all the forcing GCMs except CNRM-CM5 consider changes in land use / land cover (Table 12.1 in Collins et al. 2013). 
TABle 1 Regional climate models and forcing global climate models used in this study. The tag of the forcing member is given. The symbols used in some figures for the different RCMs are given after the RCM name.

\begin{tabular}{|c|c|c|c|c|c|c|}
\hline & CNRM-CM5 & EC-EARTH & $\begin{array}{l}\text { IPSL- } \\
\text { CM5A-MR }\end{array}$ & $\begin{array}{l}\text { HadGEM2- } \\
\text { ES }\end{array}$ & $\begin{array}{l}\text { MPI-ESM- } \\
\text { LR }\end{array}$ & NorESM1-M \\
\hline $\begin{array}{l}\text { CNRM } \\
\text { (plus) }\end{array}$ & $\mathrm{X}(\mathrm{r} 1 \mathrm{i} 1 \mathrm{p} 1)$ & & & & & \\
\hline $\begin{array}{l}\text { CNRM } \\
\text { (plus) }\end{array}$ & $\mathrm{X}(\mathrm{r} 1 \mathrm{i} 1 \mathrm{p} 1)$ & & & $\mathrm{X}(\mathrm{r} 1 \mathrm{i} 1 \mathrm{p} 1)$ & & \\
\hline $\begin{array}{l}\text { CLMcom CCLM4-8- } \\
17 \text { (star) }\end{array}$ & $\mathrm{X}(\mathrm{r} 1 \mathrm{i} 1 \mathrm{p} 1)$ & $\mathrm{X}(\mathrm{r} 12 \mathrm{i} 1 \mathrm{p} 1)$ & & $\mathrm{X}(\mathrm{r} 1 \mathrm{i} 1 \mathrm{p} 1)$ & $\mathrm{X}(\mathrm{r} 1 \mathrm{i} 1 \mathrm{p} 1)$ & \\
\hline SMHI RCA4 (circle) & $\mathrm{X}(\mathrm{r} 1 \mathrm{i} 1 \mathrm{p} 1)$ & $\mathrm{X}(\mathrm{r} 12 \mathrm{i} 1 \mathrm{p} 1)$ & $\mathrm{X}(\mathrm{r} 1 \mathrm{i} 1 \mathrm{p} 1)$ & $\mathrm{X}(\mathrm{r} 1 \mathrm{i} 1 \mathrm{p} 1)$ & $\mathrm{X}(\mathrm{r} 1 \mathrm{i} 1 \mathrm{p} 1)$ & $\mathrm{X}(\mathrm{r} 1 \mathrm{i} 1 \mathrm{p} 1)$ \\
\hline $\begin{array}{l}\text { KNMI RACMO22E } \\
\text { (X sign) }\end{array}$ & $\mathrm{X}(\mathrm{r} 1 \mathrm{i} 1 \mathrm{p} 1)$ & $\mathrm{X}(\mathrm{r} 12 \mathrm{i} 1 \mathrm{p} 1)$ & & $\mathrm{X}(\mathrm{r} 1 \mathrm{i} 1 \mathrm{p} 1)$ & & $\mathrm{X}(\mathrm{r} 1 \mathrm{i} 1 \mathrm{p} 1)$ \\
\hline $\begin{array}{ll}\text { DMI } & \text { HIRHAM5 } \\
\text { (square) } & \end{array}$ & $\mathrm{X}(\mathrm{r} 1 \mathrm{i} 1 \mathrm{p} 1)$ & $\mathrm{X}(\mathrm{r} 3 \mathrm{i} 1 \mathrm{p} 1)$ & & $\mathrm{X}(\mathrm{r} 1 \mathrm{i} 1 \mathrm{p} 1)$ & & $\mathrm{X}(\mathrm{r} 1 \mathrm{i} 1 \mathrm{p} 1)$ \\
\hline $\begin{array}{l}\text { IPSL WRF331F (up- } \\
\text { ward triangle) }\end{array}$ & & & $\mathrm{X}(\mathrm{r} 1 \mathrm{i} 1 \mathrm{p} 1)$ & & & \\
\hline $\begin{array}{l}\text { MPI-CSC } \\
\text { REMO2009 (down- } \\
\text { ward triangle) }\end{array}$ & & & & & $\mathrm{X}(\mathrm{r} 1 \mathrm{i} 1 \mathrm{p} 1)$ & \\
\hline $\begin{array}{l}\text { GERICS REMO2015 } \\
\text { (downward triangle) }\end{array}$ & & & & & $\mathrm{X}(\mathrm{r} 1 \mathrm{i} 1 \mathrm{p} 1)$ & \\
\hline
\end{tabular}

\subsection{Methods to compare GCMs and RCMs}

The GCMs are first conservatively interpolated on a common grid at a $1.5^{\circ} \times 1.5^{\circ}$ resolution. For the maps, all the grids points are interpolated. For the spatial averages over land, which are computed after interpolation on the common grid, only the points with a fraction of land greater than 0.75 are interpolated. The average evaporation over the Mediterranean sea is computed after the interpolation of the grid points with a fraction of land less than 0.25 . The Mediterranean sea is defined as the sea points between $30^{\circ} \mathrm{N}, 45^{\circ} \mathrm{N},-5^{\circ}$ E, $35^{\circ}$ E. Spatial averages over continental Europe are computed for the land points between $42^{\circ} \mathrm{N}, 52^{\circ} \mathrm{N},-5^{\circ} \mathrm{E}, 30^{\circ} \mathrm{E}$ (red box in Figure 1e). The same definitions of land and sea points are used for the RCMs.

The box in the box-and-whiskers plots shown in this paper are delimited by the 25 th and 75 th percentiles with the median in between. The whiskers extend to the minimum and maximum of the sample.

Some driving GCMs are more represented in the EURO-CORDEX ensemble (Table 1). For example, IPSL-CM5A-MR only drives two RCMs, while CNRM-CM5 forces six RCMs. In order to compare fairly the results of RCMs to their driving GCMs, the driving GCMs are weighted according to the number of RCMs they force. A GCM that forces $n$ RCMs receives a weight of $n$ in 
TABLE 2 List of CMIP5 simulations analysed in this study

\begin{tabular}{|c|c|c|}
\hline & Historical + RCP8.5 & with $\mathrm{AOD}$ at $550 \mathrm{~nm}$ \\
\hline ACCESS1-0 & $\mathrm{x}$ & $\mathrm{x}$ \\
\hline ACCESS1-3 & $\mathrm{x}$ & $\mathrm{x}$ \\
\hline bcc-csm1-1-m & $\mathrm{x}$ & \\
\hline bcc-csm1-1 & $\mathrm{x}$ & \\
\hline BNU-ESM & $\mathrm{x}$ & $\mathrm{x}$ \\
\hline CanESM2 & $\mathrm{x}$ & \\
\hline CCSM4 & $\mathrm{x}$ & \\
\hline CESM1-BGC & $\mathrm{x}$ & \\
\hline CESM1-CAM5 & $\mathrm{x}$ & $\mathrm{x}$ \\
\hline CESM1-WACCM & $\mathrm{x}$ & \\
\hline CMCC-CM & $\mathrm{x}$ & \\
\hline CMCC-CMS & $\mathrm{x}$ & \\
\hline CMCC-CESM & $\mathrm{x}$ & \\
\hline CNRM-CM5 & $\mathrm{x}$ & \\
\hline CSIRO-Mk3-6-0 & $\mathrm{x}$ & $\mathrm{x}$ \\
\hline EC-EARTH & $\mathrm{x}$ & \\
\hline FGOALS-g2 & $\mathrm{x}$ & \\
\hline FIO-ESM & $\mathrm{x}$ & \\
\hline GFDL-CM3 & $\mathrm{x}$ & $\mathrm{x}$ \\
\hline GFDL-ESM2G & $\mathrm{x}$ & $\mathrm{x}$ \\
\hline GFDL-ESM2M & $\mathrm{x}$ & $\mathrm{x}$ \\
\hline GISS-E2-H & $\mathrm{x}$ & \\
\hline GISS-E2-R & $\mathrm{x}$ & \\
\hline HadGEM2-CC & $\mathrm{x}$ & $\mathrm{x}$ \\
\hline HadGEM2-ES & $\mathrm{x}$ & $\mathrm{x}$ \\
\hline inmem4 & $\mathrm{x}$ & \\
\hline IPSL-CM5A-LR & $\mathrm{x}$ & \\
\hline IPSL-CM5A-MR & $\mathrm{x}$ & $\mathrm{x}$ \\
\hline IPSL-CM5B-LR & $\mathrm{x}$ & \\
\hline MIROC5 & $\mathrm{x}$ & \\
\hline MIROC-ESM & $\mathrm{x}$ & $\mathrm{x}$ \\
\hline MIROC-ESM-CHEM & $\mathrm{x}$ & $\mathrm{x}$ \\
\hline MPI-ESM-LR & $\mathrm{x}$ & \\
\hline MPI-ESM-MR & $\mathrm{x}$ & \\
\hline MRI-CGCM3 & $\mathrm{x}$ & $\mathrm{x}$ \\
\hline NorESM1-M & $\mathrm{x}$ & $\mathrm{x}$ \\
\hline NorESM1-ME & $\mathrm{x}$ & \\
\hline
\end{tabular}

the ensemble mean (unless otherwise specified). Following the same approach, for the boxplots depicting the inter-model distribution of the driving GCMs, the change projected by a GCM used to forced $n$ RCMs is repeated $n$ times before computing the distribution. As a result, multiple identical values exist in the forcing GCM distribution, which explains why the median of the boxplots can be equal to the 25 th or 75 th centile, or the minimum equal to the 25 th percentile.

\subsection{Changes in solar radiation inferred from changes in cloud cover}

Clear sky downwelling shortave radiation at surface (RSDS) is unfortunately not available for the RCMs and some forcing GCMs. In order to approximately assess to what extent the differences in cloud cover changes impact the differences in RSDS changes, the following approach is followed. For each RCM and GCM separately and at each point, JJA cloud cover and RSDS on 
the 1960-2004 period are linearly detrended. RSDS is then linearly regressed on cloud cover. At each point, the regression coefficient obtained is finally multiplied by the future changes in cloud cover in order to assess the change in RSDS inferred from the simple change in cloud cover, assuming no change in the relationship between cloud cover and RSDS, i.e. no change in cloud properties (except for cloud cover). The subtraction of RSDS changes inferred from cloud cover from total RSDS changes gives an estimate of the impact of aerosols, water vapor and cloud properties unrelated to cloud cover on changes in RSDS. This value is not exactly comparable to the change in clear sky RSDS as cloud cover is indeed not the only cloud property that plays in the cloud / solar radiation relationship. For example, the nature and altitude of the clouds are also important and may change in the future climate. A part of the indirect effects of aerosols on solar radiation through changes in cloud properties simulated by some models (Section 2.1) is therefore also likely included in the Total minus Inferred RSDS estimates.

\subsection{Sensitivity experiments}

In section 4.2 , we analyse the results of a sensitivity experiment with the latest version of the ALADIN regional climate model (CNRM-ALADIN63, Table 1). The standard historical and RCP8.5 simulations on the 1951-2100 period forced by CNRM-CM5 (Table 1) are used as a reference. As previously said, the same time-varying aerosol forcing as in CNRM-CM5 is used for these simulations. Following a protocol defined in the dedicated CORDEX Flagship Pilot Study (FPS), the so-called FPS-aerosol, a twin simulation on the 20212050 period with a constant anthropogenic aerosol forcing has also been run with CNRM-ALADIN63. The aerosol optical depth of CNRM-CM5 from the historical simulation averaged on the 1971-2000 period is used. The lateral boundary conditions are the same as in the standard run. This simulation therefore allows to quantify the impact of not considering the time-variations of anthropogenic aerosols on the simulated changes on the 2021-2050 period. Note that this period, set by the FPS-aerosol protocol, is not the same as the one generally used in the rest of the study.

\section{Differences of projected temperature and precipitation}

The general pattern of future temperature and precipitation changes in summer over Europe is now well known (e.g. Collins et al. 2013, Terray and Boé 2013), with an amplification of surface warming over southern Europe associated with a large decrease in precipitation, and an increase in precipitation over Scandinavia. Both the RCMs and their driving GCMs exhibit such a pattern (Figure 1). Some important differences between them are however noted, especially regarding the intensity of the changes.

A smaller warming of at least $1 \mathrm{~K}$ is indeed simulated by the RCMs compared to their driving GCMs over most of Europe, and differences as large as 
(a) $2 \mathrm{~m}$ Temperature RCMs

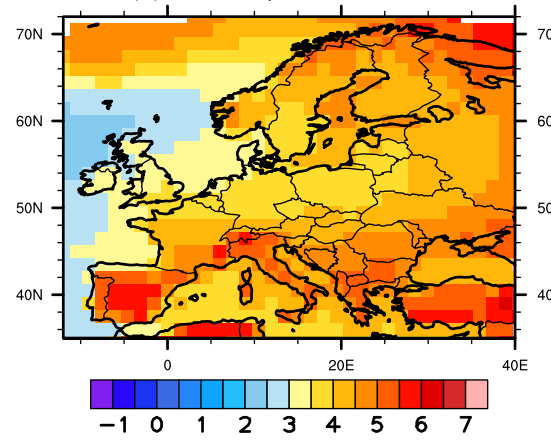

(c) $2 \mathrm{~m}$ Temperature GCMs

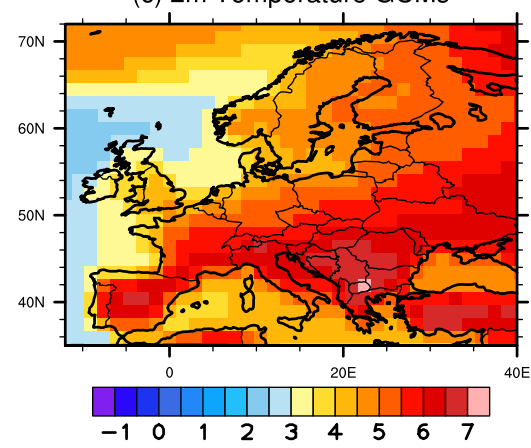

(e) Diff RCMs-GCMs

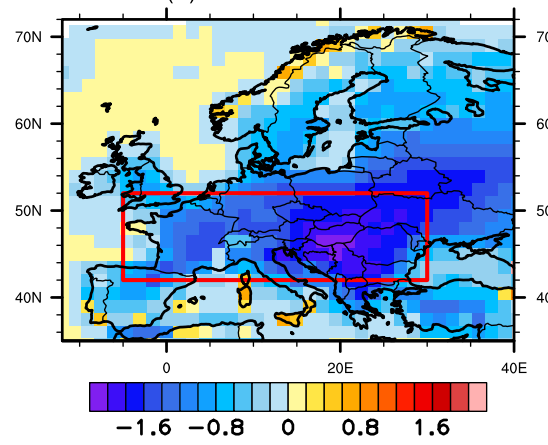

(b) Precipitation RCMs

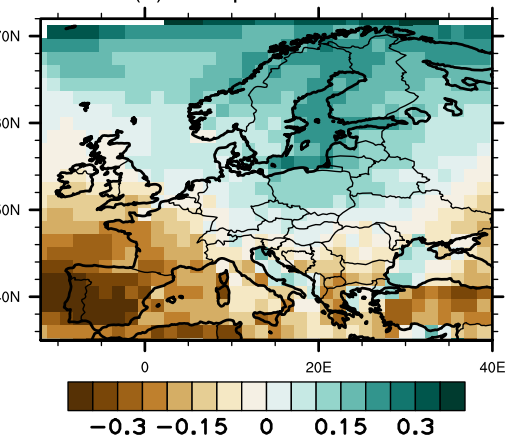

(d) Precipitation GCMs

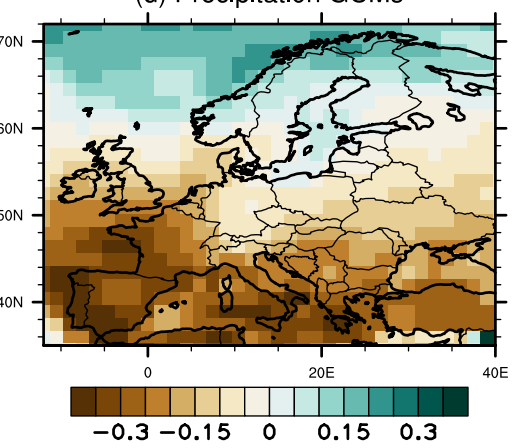

(f) Diff RCMs-GCMs

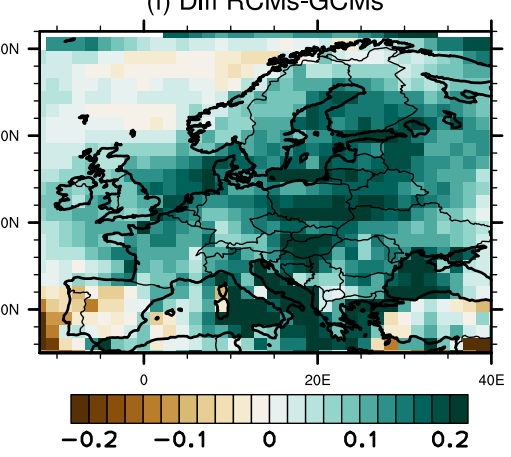

Figure 1 Ensemble mean changes in summer temperature (K) over Europe between 20702099 and 1970-1999 as (a) projected by the RCMs, as (c) projected by their driving GCMs, and (e) differences ((a)-(c)). The GCMs are weighted according to the number of RCMs they force. $b, d, f:$ same as a,c,e for relative summer precipitation changes (no unit). The red box in (e) shows the domain used for the calculation of the spatial averages over Europe in the paper (note than only land points are used; see also section 2). 
(a) Temperature

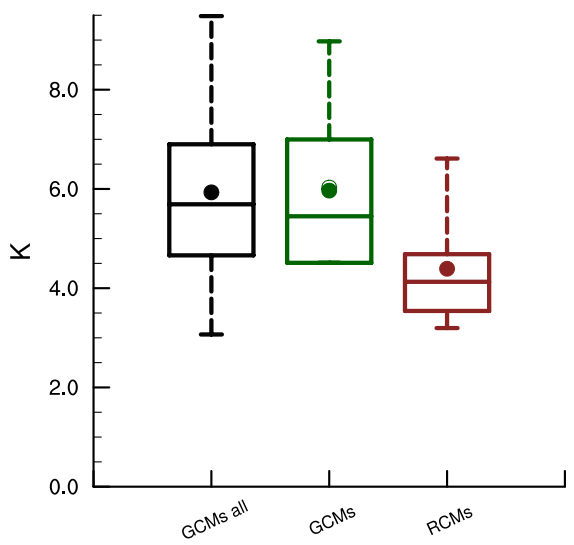

(b) Precipitation

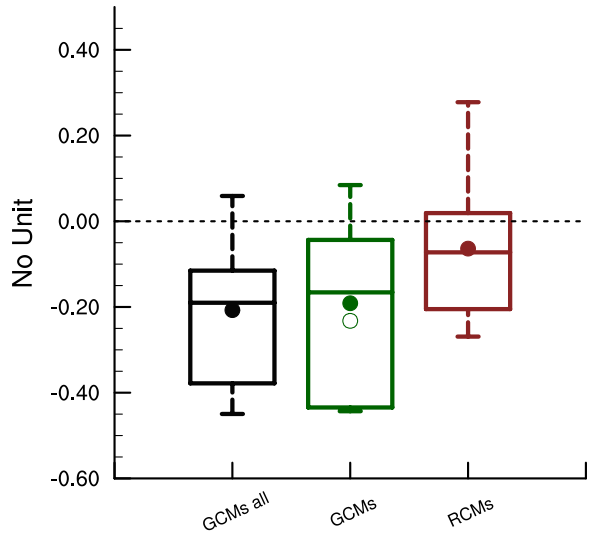

Figure 2 Intermodel distribution of (a) changes in summer temperature (K) and (b) relative changes in summer precipitation (no unit), averaged over Europe (land points within the red box in Figure 1e), in the complete ensemble of CMIP5 models ("GCMs all"), in the CMIP5 models used to drive the $12 \mathrm{~km}$ EURO-CORDEX RCMs ("GCMs") and in the RCMs ("RCMs"). The differences between 2070-2099 and 1970-1999 are calculated. See the description of the boxplots in Section 2. Circles : ensemble means. For the forcing GCMs, the empty circle shows the unweighted ensemble mean. The filled circles show the weighted ensemble mean, according to the number of RCMs forced by each GCM.

$2 \mathrm{~K}$ are noted over the south of eastern Europe (Figure 1e). The smaller differences are seen over Spain, Great Britain and Scandinavia, with differences close or inferior to $1 \mathrm{~K}$. Large differences in precipitation changes, between $10 \%$ and $20 \%$, are also seen over a large part of Europe, the main exception being Spain (Figure 1f). The sign of precipitation anomalies is even different in the RCMs and in their driving GCMs over the north of central Europe.

The larger differences of temperature and precipitation changes over land are generally seen in a band approximately between $42^{\circ} \mathrm{N}$ and $52^{\circ} \mathrm{N}$, and $-5^{\circ} \mathrm{E}$ and $30^{\circ} \mathrm{E}$ (red box in Figure 1e), which we use throughout the paper for the 
calculation and analysis of spatial averages. This area is named "Europe" for the sake of simplicity.

Six GCMs among the nearly 40 CMIP5 models have been used to drive the $12 \mathrm{~km}$-resolution RCMs in the EURO-CORDEX project (Table 1). The selection of these six models has been mainly ad-hoc and not based on the type of methodologies proposed by McSweeney et al. (2015) or Monerie et al. (2017) to ensure the representativeness of the sub-sample. The driving GCMs may therefore not be representative of the full CMIP5 ensemble, which would have important consequences for the results of the EURO-CORDEX ensemble. As shown by Déqué et al. (2012) based on previous RCMs, the forcing GCMs indeed explain an important part of the dispersion of regional projections, for example roughly $1 / 3$ of the variance for summer precipitation changes over Europe and $2 / 3$ for summer temperature changes.

The multi-model averages of future summer temperature and precipitation changes over Europe are very similar between the driving GCMs (unweighted or weighted according to the number of RCMs forced) and the full ensemble of CMIP5 GCMs (Figure 2a). With regard to the ensemble mean changes, the sub-sample of GCMs used to force the RCMs is therefore adequate. However, some differences of distributions are seen. No CMIP5 model with a small warming (less than $4.5 \mathrm{~K}$ ) has been used to force the RCMs. This type of large scale temperature change is therefore not regionalized within the EURO-CORDEX ensemble. Regional simulations forced by GFDL-ESM2G, GISS-E2-R, MRICGCM3, or inmcm4, which show a small warming over Europe in summer (not shown), would be interesting to complete the EURO-CORDEX ensemble.

As we are firstly interested in understanding the physical mechanisms responsible for the differences between RCMs and GCMs, we focus on the differences between the RCMs and their driving GCMs only. The spatial averages confirm that summer warming is much greater in the driving GCMs than in the RCMs, with a clear shift of the RCM distribution towards lesser warming (Figure 2a). The ensemble mean change is close to $6 \mathrm{~K}$ for the GCMs and close to $4 \mathrm{~K}$ for the RCMs, i.e. $50 \%$ larger in the GCMs. While some GCMs simulate warmings close to $9 \mathrm{~K}$, surface warming never reaches $7 \mathrm{~K}$ in the RCMs. The smaller warming of the RCMs compared to their forcing GCMs noted here is consistent with the results of Sorland et al. (2018), who also found a smaller warming projected by two EURO-CORDEX RCMs forced by several GCMs. Note that in the distribution of temperature changes in the forcing GCMs, the minimum is equal to the 25th percentile because of the replication of values necessary to give to each GCM a weight proportional to the number of RCMs forced, as explained in Section 2.3.

The ensemble mean decrease of precipitation is also almost 4 times greater in the driving GCMs than in the RCMs over western Europe (-20\% versus $-5 \%$, Figure $2 \mathrm{~b}$ ). More than $25 \%$ of RCM projections show an increase in precipitation, as large as 30\% in WRF331F. Only $8 \%$ of the GCMs (full CMIP5 ensemble) show an increase in precipitation and this increase never exceeds $5 \%$. 


\section{Role of shortwave radiation and anthropogenic aerosols}

\subsection{Analysis of EURO-CORDEX and CMIP5 projections}

As noted in Section 2, most EURO-CORDEX projections do not account for the time-evolution of anthropogenic aerosols contrary to the CMIP5 models. It could be problematic because large future changes in AOD are expected over most of Europe (Myhre et al. (2013) and Figure 3). The concentration of anthropogenic aerosols, dominated by sulfate aerosols, indeed peaked over Europe at the end of the 1970s and has decreased since then, as a result of anti-pollution measures (Wild 2009). Nabat et al. (2014), with a coupled ocean-atmosphere regional model based on ALADIN53, have shown that this decrease of AOD had a strong impact on the European climate past trends, and explains roughly $80 \%$ (25\%) of the trends in shortwave radiation at surface (temperature, respectively) on the 1980-2012 period. The direct effect of aerosols, namely the scattering on incident solar radiation, is indeed responsible on this period of a brightening phenomenon, causing an extra warming at surface. The decrease of AOD is expected to continue through the 21st century, at a much smaller rate after 2030-2040 (e.g. see Supplementary Figure 3 in Boé 2016). In any case, the AOD is generally much smaller in the CMIP5 GCMs at the end of the 21st century than at the end of the 20th century (Figure $3 a)$. The larger decrease of AOD (-0.4, which roughly corresponds to - $80 \%$ ) is seen over central Europe. The evolution of AOD described here lies in the RCP emission scenarios, which have important uncertainties and make strong assumptions regarding the future emissions of aerosols (e.g. see discussion in Bellucci et al. (2015)). These scenarios do not cover the full range of potential future evolutions of aerosols. For example, air quality policies are supposed to become more stringent over time as a result of rising income levels (van Vuuren et al. 2011), which may not be the case in practice.

Not surprisingly, as aerosols are the dominant driver of changes in RSDS in clear sky conditions, clear sky RSDS increases over most of Europe in the CMIP5 GCMs (Figure 3b). This increase is maximal over eastern Europe (Czech Republic, Slovakia and Poland) where it reaches 10-15 W.m $\mathrm{m}^{-2}$. Shortwave radiation at surface in clear sky conditions is also impacted by water vapor. However, AOD changes explain most of the inter-model spread in clear sky RSDS changes over Europe (Figure 3d, $\mathrm{r}=-0.88$ ), and water vapor therefore plays a much lesser role in that context. Additionally, the value of clear sky RSDS changes that corresponds to no change in AOD based on the regression line in Figure 3d, and is therefore an estimation of the role of water vapor, is roughly $-2.5 \mathrm{~W} \cdot \mathrm{m}^{-2}$. The small decrease in clear sky RSDS over sea away from the continent, where AOD does not evolve much, still can be attributed to the increase in atmospheric water wapor (e.g. Figure 12). Because of water vapor, the direct impact of anthropogenic aerosols on clear sky RSDS over land is actually greater than the anomalies shown in Figure $3 \mathrm{~b}$.

Note that the forcing GCMs for which the AOD is available have intermediary values of AOD changes (Figure 3d, see also legend) and therefore of 
(a) AOD

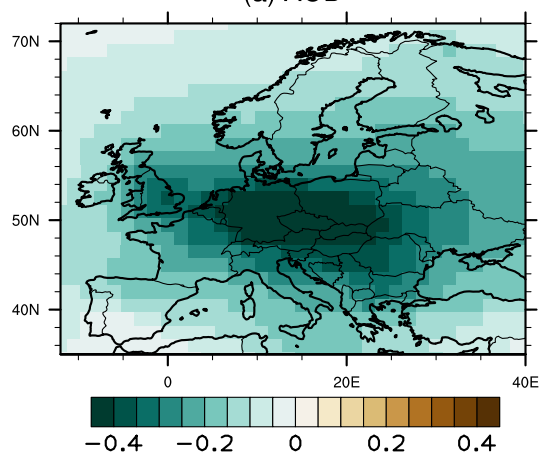

(c) Solar

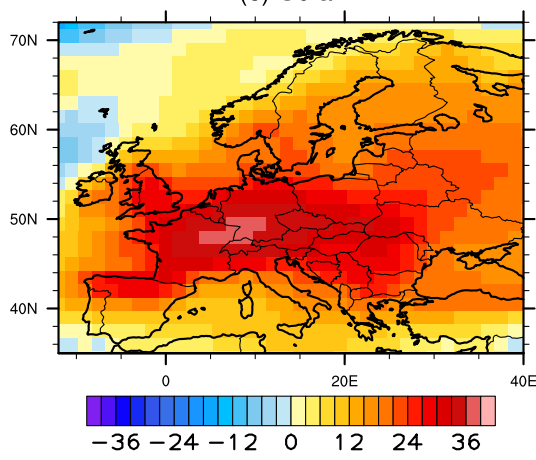

(b) Clear Sky Solar

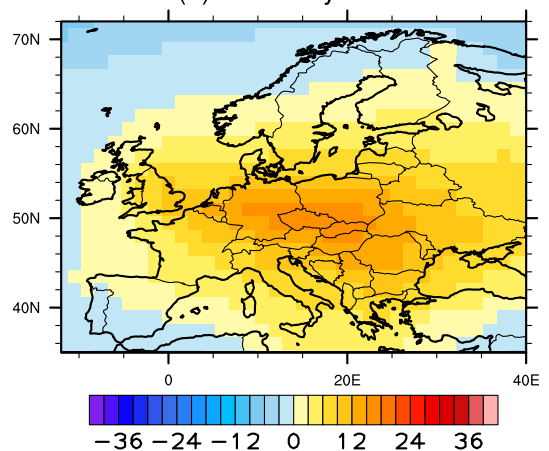

(d)

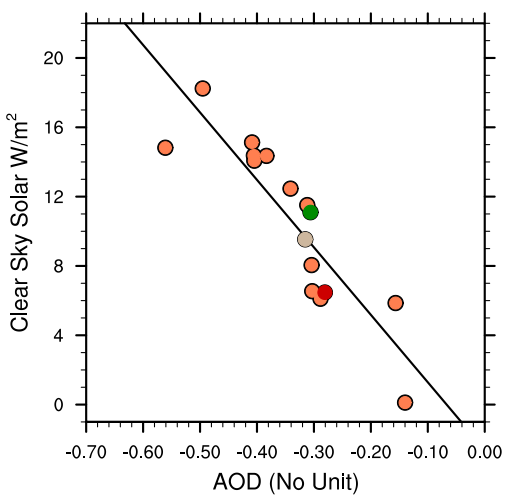

Figure 3 (a) Ensemble mean changes in the aerosols optical depth at $550 \mathrm{~nm}$ for ambient aerosols (no unit) in an ensemble of 16 CMIP5 models for which this variable is available (see Section 2). (b) same as (a) for clear sky RSDS $\left(W \cdot m^{-2}\right)$. (c) same as (a) for RSDS $\left(W \cdot m^{-2}\right)$. (d) scatter plot of the changes in clear sky RSDS versus changes in AOD at $550 \mathrm{~nm}$ averaged over Europe (land points within the red box in Figure 1e). Each point is a CMIP5 model. Models used to drive the RCMs and for which AOD is available are highlighted : the green point corresponds to HadGEM2-ES, the light brown point to NorESM1-M and the red point to IPSL-CM5A-MR. The change of AOD in CNRM-CM5 is -0.34 and in EC-EARTH is 0.28 . These two models are not on the scatter plot as clear sky RSDS is not available. The differences between 2070-2099 and 1970-1999 are calculated.

clear sky RSDS changes (between 7 and $11 W^{-2} \cdot m^{-2}$ ). The EURO-CORDEX RCMs do not provide clear sky RSDS and therefore they cannot be compared to their driving GCMs. As all EURO-CORDEX RCMs except ALADIN and RACMO do not take into account the time evolution of anthropogenic aerosols, we don't expected large changes in clear sky RSDS for most regional projections, except for a small decrease due to water vapor.

Total sky RSDS also strongly increases over Europe in the CMIP5 models (Figure 3c). Over eastern Europe, clear sky RSDS changes represent up to 
roughly half of the change in total RSDS, which is especially large there (greater than $30 \mathrm{~W} \cdot \mathrm{m}^{-2}$, Figure $3 \mathrm{c}$ ). The relative importance of clear sky changes compared to total sky changes is smaller over western Europe, especially over France, suggesting an important decrease of cloud cover there. For the 16 CMIP5 GCMs that provide both AOD and clear sky RSDS (see Table 3) used in Figure 3, the decrease of RSDS in clear sky conditions explains $1 / 3$ of the change in all sky conditions over our domain of interest $\left(10 \mathrm{~W} . \mathrm{m}^{-2}\right.$ versus 30 $\left.W \cdot m^{-2}\right)$.

Very large differences in RSDS changes between the RCMs and their driving GCMs are noted (Figure 4a), consistently with Bartok et al. (2017) and Gutierrez-Escribano et al. (in review) who have noted a large difference in RSDS changes between EURO-CORDEX RCMs and their driving GCMs for annual means. The driving GCMs simulate an increase of RSDS of $25 \mathrm{~W} \cdot \mathrm{m}^{-2}$ over Europe, while in average the RCMs simulate an increase of RSDS as small as $5 \mathrm{~W} . \mathrm{m}^{-2}$ over the same area (Figure 4a). Also consistently with Bartok et al. (2017), important differences in cloud cover changes exist between the RCMs and their driving GCMs. While the decrease is close to $6 \%$ over Europe in the GCMs, it is close to $4 \%$ in the RCMs (Figure 4b; Figure 5a,c).

Inferred changes in RSDS from the changes in cloud cover (see Section 2.3 for a description of the methodology) are now studied. Important changes in inferred RSDS are projected over western Europe, France in particular, where the decrease of cloud cover is large, especially in the GCMs (e.g. $20 \mathrm{~W} \cdot \mathrm{m}^{-2}$ over France in the GCMs and $10 \mathrm{~W} \cdot \mathrm{m}^{-2}$ in the RCMs, Figure 5). The inferred changes in RSDS are generally larger in the GCMs, because the decrease of cloud cover is also larger (Figure 5a,c). Note that in Figure 5f, only the forcing GCMs are considered, which explains why the results in Figure 5 f and Figure 3, which uses a larger sample of GCMs, are different, with smaller RSDS changes in the sub-sample of GCMs used to force the RCMs.

The total changes of RSDS in the RCMs (full ensemble) are generally smaller than the ones inferred from changes in cloud cover alone, although the difference is generally small except over the north of the domain (Figure 5j). The behaviour of the driving GCMs is generally very different. Except over southern Spain and northern Scandinavia, the total changes of RSDS are indeed greater, and sometimes much greater as over eastern Europe (differences as large as $15 \mathrm{~W} \cdot \mathrm{m}^{-2}$ ), than the changes inferred from changes in cloud cover alone.

The changes in cloud cover and inferred RSDS are similar in RACMO and ALADIN compared to the full RCM ensemble (Figure 5a,b and g,h). However, a much stronger increase in total RSDS is noted in RACMO and ALADIN (Figure 5d,e), with strong positive differences between total and inferred RSDS changes over most of Europe, much more similar to what is seen in the GCMs than in the full RCMs ensemble. An exception concerns a few points in the Alps. It is probably due to the fact the orography is higher in the RCMs than in the GCMs, with therefore a much smaller impact of aerosols at surface. 
(a) Shortwave radiation

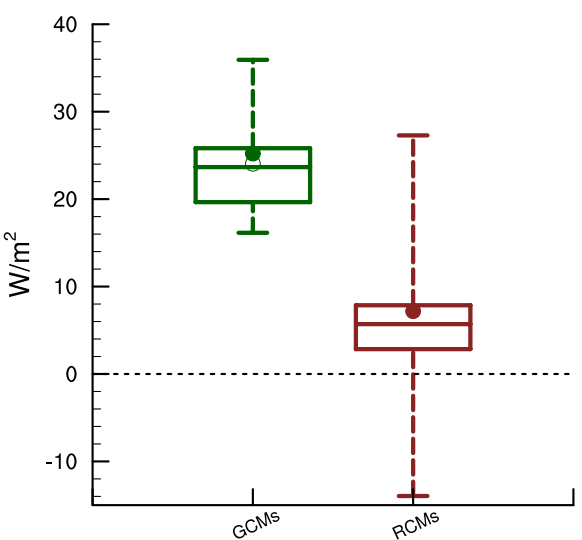

(b) Cloud cover

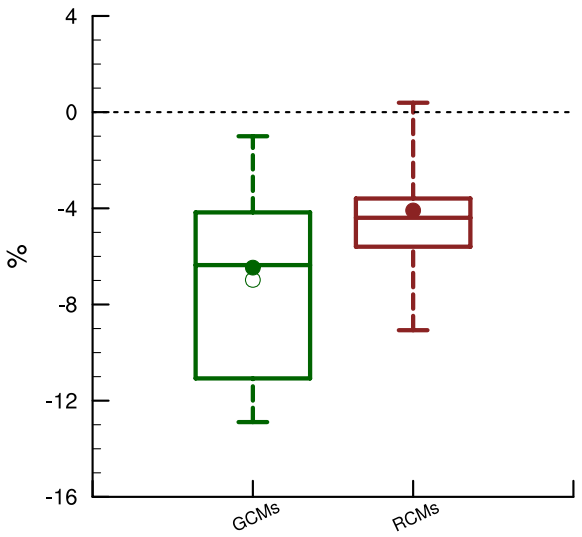

Figure 4 Intermodel distribution of changes in (a) summer downwelling shortwave radiation at surface $\left(W \cdot m^{-2}\right)$ and (b) summer cloud cover (\%), averaged over Europe (land points within the red box in Figure 1e) in the CMIP5 models used to drive the RCMs and in the RCMs, See section 2 for the details on the boxplots. Circles : ensemble means. For the forcing GCMs, the empty circle shows the unweighted ensemble mean. The filled circle shows the weighted ensemble mean, according to the number of RCMs forced by each GCM. The differences between 2070-2099 and 1970-1999 are calculated.

The much larger increase in solar radiation at surface noted in ALADIN and RACMO compared to the other RCMs (Figure 5d,e) is therefore not mainly explained by cloud cover : anthropogenic aerosols play an important role, as concluded by Gutierrez-Escribano (in review).

Consistently with the large direct impact of anthropogenic aerosols on RSDS in the GCMs noted previously (Figure 3), this analysis shows that cloud cover changes alone don't explain the totality of the differences in RSDS changes between RCMs (without time-varying aerosol concentrations) and GCMs, as large differences remain after controlling for the impact of cloud cover changes. 

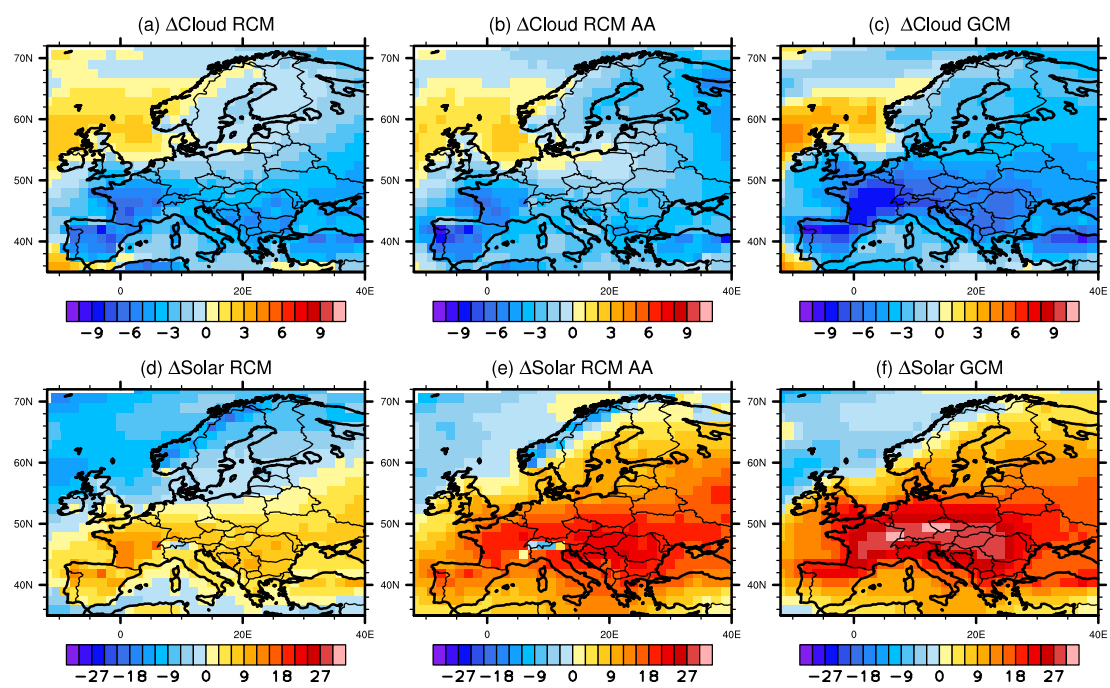

(e) $\triangle$ Solar RCM AA

(f) $\triangle$ Solar GCM
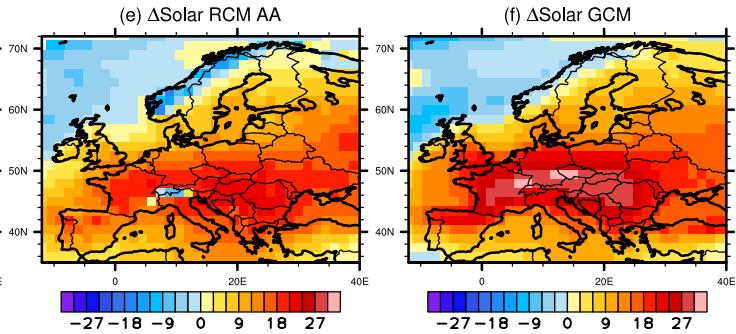

(g) Inf. $\triangle$ Solar RCM

(h) Inf. $\triangle$ Solar RCM AA

(i) Inf. $\Delta$ Solar GCM
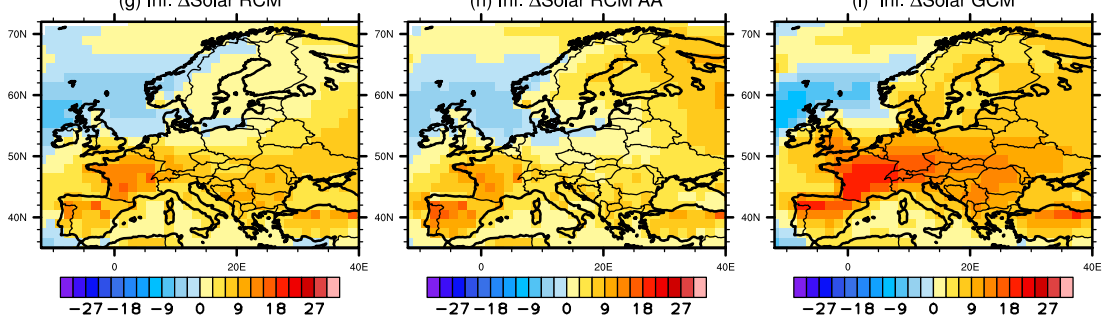

(k) Diff RCM AA

(I) Diff GCM
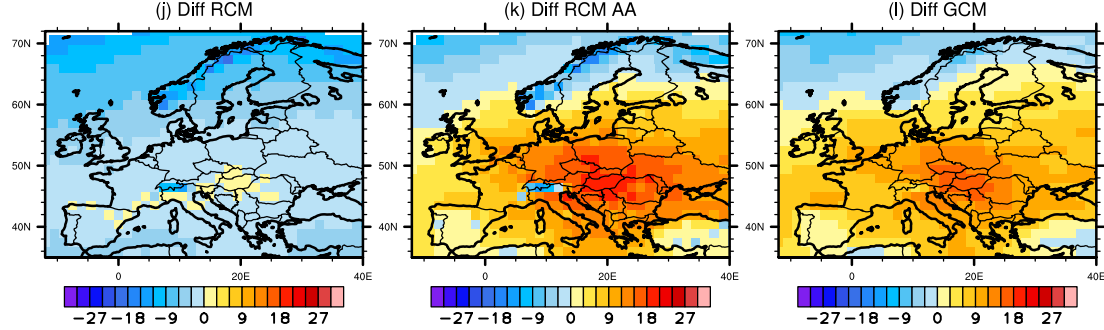

Figure 5 Future ensemble mean changes in summer between 2070-2099 and 1970-1999 of cloud cover (\%) in (a) the full ensemble of RCMs, (b) in RACMO and ALADIN, and (c) the driving GCMs. (d) to (f) same as (a) to (c) for downwelling shortwave radiation at surface $\left(W \cdot m^{-2}\right)$. Inferred changes between 2099-2070 and 1999-1970 in downwelling shortwave radiation at surface $\left(W \cdot \mathrm{m}^{-2}\right)$ according to the simple change in cloud cover in (g) the full ensemble of RCMs, (h) in RACMO and ALADIN, and (i) the driving GCMs. See Section 2 for details. Differences between changes in downwelling shortwave radiation at surface and inferred changes $\left(W \cdot m^{-2}\right)$ in (j) the full ensemble of RCMs, $(\mathrm{k})$ in RACMO and ALADIN, and (l) the driving GCMs. Note that IPSL WRF3.11 is not used in the RCMs because cloud cover is not available for this model. 
TABle 3 Future ensemble mean changes in summer between 2070-2099 and 1970-1999 averaged over Europe of total downwelling shortwave radiation at surface (Total), inferred from cloud cover changes in downwelling shortwave radiation at surface (Inferred), difference between the two (Inferred-Total) and ratio ((Total-Inferred)/Total). The multi-model average and standard deviation (between brackets) are given. The domain used for the spatial average is the red box in Figure 1e. "Forcing GCMs" corresponds to the forcing GCMs weighted by the number of RCMs forced, "Forcing GCMs of ALADIN and RACMO" corresponds to the forcing GCMs of ALADIN and RACMO weighted by the number of RCMs forced, "ALADIN and RACMO" corresponds to the seven regional climate simulations with either ALADIN or RACMO (see Table 1), "Other RCMs" corresponds to the regional simulations with the other RCMs. "All RCMs" corresponds to all RCMs. Note that the results of IPSL WRF3.11 and of its forcing GCM are not included in these results because cloud cover is not available in IPSL WRF3.11.

\begin{tabular}{|l||l|l|l|l|l|}
\hline & $\begin{array}{l}\text { Forcing } \\
\text { GCMs }\end{array}$ & $\begin{array}{l}\text { Forcing } \\
\text { GCMs } \\
\text { of ALADIN } \\
\text { and RACMO }\end{array}$ & $\begin{array}{l}\text { ALADIN } \\
\text { and RACMO }\end{array}$ & $\begin{array}{l}\text { Other } \\
\text { RCMs }\end{array}$ & All RCMs \\
\hline Total $\left(W . m^{-2}\right)$ & $25.6(6.0)$ & $26.9(6.4)$ & $18.6(7.3)$ & $3.5(3.8)$ & $8.1(8.7)$ \\
\hline $\begin{array}{l}\text { Inferred } \\
\left(W . m^{-2}\right)\end{array}$ & $13.9(10.8)$ & $10.6(10.5)$ & $5.1(3.8)$ & $8.6(3.3)$ & $7.5(3.8)$ \\
\hline $\begin{array}{l}\text { Total-Inferred } \\
\left(W . m^{-2}\right)\end{array}$ & $11.7(9.8)$ & $16.3(6.2)$ & $13.5(7.6)$ & $-5.0(2.7)$ & $0.6(9.9)$ \\
\hline $\begin{array}{l}\text { (Total- } \\
\text { Inferred)/Total } \\
\text { (No Unit) }\end{array}$ & $0.46(0.41)$ & $0.64(0.30)$ & $0.73(0.25)$ & $-0.75(7.7)$ & $-0.29(6.4)$ \\
\hline
\end{tabular}

Table 3 synthesises the main results of Figure 5 for our domain of interest. Considering the difference between total and inferred from clouds RSDS changes as an approximate estimate of the impact of anthropogenic aerosols (within the limitation discussed in Section 2.3 ; i.e. the inclusion of the impact of water vapor and changes in cloud properties unrelated to cloud cover), aerosols would explain in ensemble mean $45 \%$ of the change in total RSDS in the forcing GCMs and $73 \%$ in the RCMs with time-varying aerosol concentrations ( $81 \%$ for ALADIN simulations and $68 \%$ for RACMO, not shown). This difference is not explained by a much greater direct impact of aerosols (as approximated by "Total-Inferred") but by smaller changes in cloud cover in these two RCMs (Figure 4) and therefore in total RSDS changes compared to many GCMs. Note also that the forcing GCMs of ALADIN and RACMO themselves generally show a smaller increase in inferred solar radiation compared to other forcing GCMs (because of a smaller decrease in cloud cover, not shown). Aerosols explain approximately $64 \%$ of the change in total RSDS in the forcing GCMs of ALADIN and RACMO, a value closer to the one of ALADIN and RACMO (73\%). The difference between total and inferred RSDS in the RCMs with constant aerosols is negative (Table 3), consistently with the dimming effect of increased water vapour content in the atmosphere.

Our conclusions differ from the one of Bartok et al. (2017) who attribute the difference between RSDS in RCMs and GCMs mainly to cloud cover. The absence of time-varying aerosols in most EURO-CORDEX RCMs is also very 
important in this context. Not coincidentally, the two RCMs with time-varying aerosols behave much more similarly to the forcing GCMs.

Note that aerosols might play an even greater role. They indeed may impact the differences in cloud cover changes between RCMs and their forcing GCMs through the indirect aerosol effects on clouds included in some GCMs (Section 2.1). They may also impact cloud cover through induced climate changes. For example, they impact the surface energy balance, and potentially the surface water balance through evapotranspiration. The associated potential changes in the vertical temperature and humidity profiles could alter the cloud cover.

The analyses in this section show that anthropogenic aerosols have a strong impact on shortwave radiation at surface in the CMIP5 models. This impact is greater than $10 \mathrm{~W} \cdot \mathrm{m}^{-2}$ from the analysis of clear sky RSDS in a larger ensemble of GCMs or $11 \mathrm{~W} \cdot \mathrm{m}^{-2}$ for the forcing GCMs based on the analysis of inferred from cloud cover changes in RSDS (Table 3), as these figures also include the dimming effect of water vapor. This clearly represents a strong perturbation of the surface energy budget. Most of the regional climate projections (17 out of 24) cannot capture this impact because they do not take into account the time variations of anthropogenic aerosols. The only two RCMs that use time-varying aerosols have an impact of aerosols of about $13.5 \mathrm{~W} . \mathrm{m}^{-2}$, close to the forcing GCMs.

Anthropogenic aerosols are therefore very likely partly responsible for the smaller warming in the RCMs than in their driving GCMs in ensemble mean, based on simple surface energy budget considerations. Not surprisingly, a strong inter-model relationship between differences in RSDS and temperature changes is noted. The greater the difference in changes in incoming shortwave radiation at surface between a RCM and its driving GCM is, the larger the difference of surface warming is (Figure $6, \mathrm{r}=0.74$ ). As shown in Figure 6b, and consistently with previous results, the inter-model differences in RSDS changes between the RCMs and their driving GCMs are weakly explained by the differences in cloud cover changes, pointing to an important role for aerosols.

Note that the ALADIN53 and ALADIN63 simulations almost do not show differences in RSDS changes with their forcing GCM (CNRM-CM5), consistant with the fact that the time-varying aerosol forcing of CNRM-CM5 is also used in the ALADIN simulations. The differences of RSDS changes between RACMO and EC-EARTH are also small, consistent with the fact that the timevarying aerosol forcing of EC-EARTH is used in the RACMO simulations. The other RACMO simulations (forced by CNRM-CM5, NorESM1-M and HadGEM2-ES, Table 1), which all use the EC-EARTH aerosol forcing, show differences in RSDS changes with their forcing GCMs, probably because of these differences in aerosols forcing to some extent. 
(a)

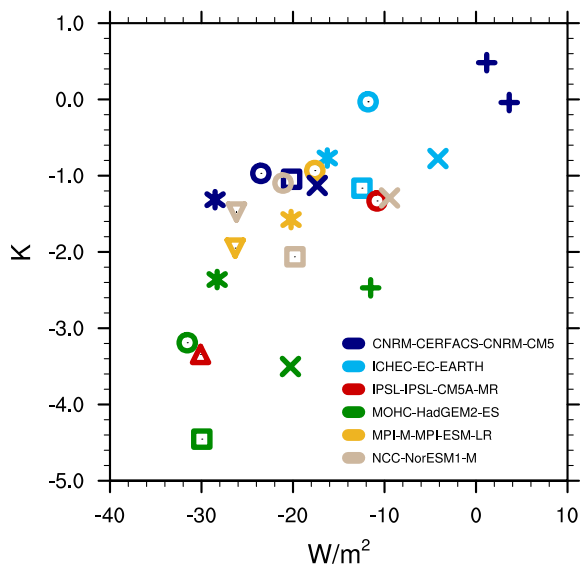

(b)

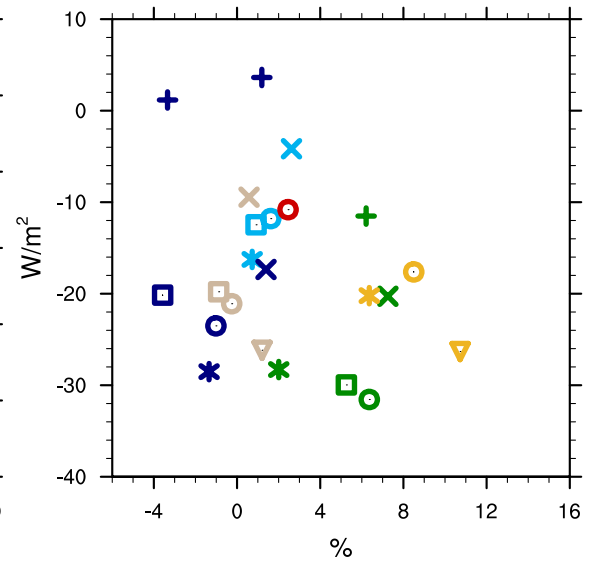

Figure 6 (a) Differences of surface temperature changes (K) between the RCMs and their forcing GCMs (RCMs-GCMs) versus differences of changes in shortwave radiation at surface $\left(W \cdot m^{-2}\right.$ ) averaged over Europe in summer (land points within the red box in Figure 1e). $\mathrm{r}=0.74$. Each symbol corresponds to a particular RCM (see Table 1) and each color to a particular forcing GCM (see legend on the graph). (b) same as (a) for differences of changes in shortwave radiation at surface $\left(W \cdot m^{-2}\right)$ versus differences of changes in cloud cover (\%). $\mathrm{r}=-0.27$

\subsection{Evaluation of past trends}

Important uncertainties exist in the future evolution of aerosol concentrations and the response of solar radiation to this evolution (e.g. Figure 3d). Obviously, it is not possible to assess the realism of future changes in solar radiation, but the evaluation of the past evolution may be very valuable, especially since strong changes have already occurred. Since the 1980s, a strong reduction of anthropogenic aerosol concentrations over Europe has indeed occurred with a consequent increase in solar radiation at surface (e.g. Wild 2009). The trends in the same observed series from the Global Energy Balance Archive (GEBA, Gilgen et al. (1998), Wild et al. (2017)) used in Nabat et al. (2014) but for summer and the stations within our domain of interest are calculated on the 1980-2005 period, and then the spatial mean is calculated (Figure 7). A strong trend in summer solar radiation at surface, greater then 7 W. $\mathrm{m}^{-2} /$ 10yrs has been observed. For the RCMs, a very large inter-model spread in the trends exists (Figure 7). The trends are small or even negative in many RCM simulations. The trends of ALADIN53 and ALADIN63 forced by CNRM-CM5 however come very close to the observed one, closer than any other regional simulation. It gives confidence in this configuration to study shortwave radiation processes. 


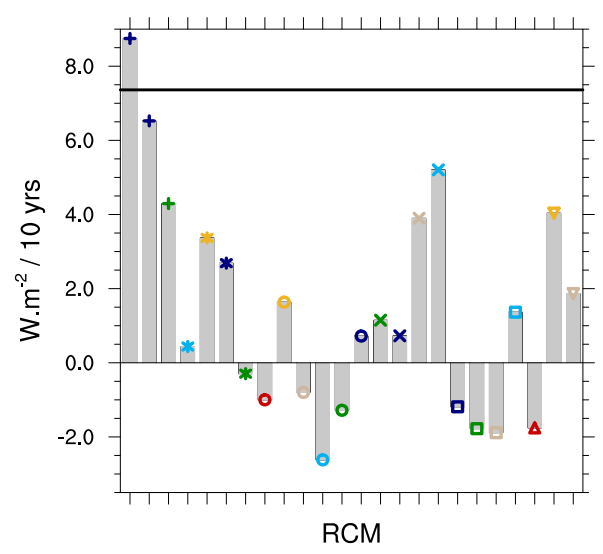

Figure 7 Trends in downwelling shortwave radiation at surface over Europe in summer on the 1980-2005 period in the RCMs and in the observations (GEBA dataset), adapting the analysis from Nabat et al. (2014) to summer and to our domain of interest. The GEBA stations within our domain of interest (red box in Figure 1e) and, for the RCMs, the grid points the closest to these stations are considered. The color code for the forcing GCM and the symbol for the RCMs are the same as in the other figures (e.g. see Figure 6 for the colors and Table 1 for the symbols).

\subsection{Results of the sensitivity experiment}

In order to further assess the impact of the absence of time-varying anthropogenic aerosol forcing, the sensitivity experiment with ALADIN63 described in Section 2.4 is analysed. This experiment follows the CORDEX FPS-aerosol protocol, which focuses on the 2021-2050 period. The standard ALADIN63 projection, with time varying aerosol forcing, is compared to the sensitivity experiment in which aerosol forcing is constant on the 2021-2050 period and equal to the 1971-2000 average.

It is clear from Section 4.1 that large model uncertainties exist regarding solar radiation processes. The aerosols-driven changes in RSDS are large in ALADIN. This RCM is at the higher end of the spectrum of values obtained for Total minus Inferred changes in RSDS : $20 \mathrm{~W} \cdot \mathrm{m}^{-2}$ in average (not shown), more than the 11.7 W.m $\mathrm{m}^{-2}$ of the forcing GCMs (Table 3 ). However, ALADIN63 forced by CNRM-CM5 simulates realistic past trends in RSDS, more realistic indeed than in any other regional simulation (Figure 7). This gives good confidence in the skill of ALADIN regarding solar radiation processes and in the aerosol forcing used in both ALADIN and CNRM-CM5, from Szopa et al. (2013). It reinforces our confidence in the results of the sensitivity experiments described in this section.

Variations of anthropogenic aerosol forcings lead to major differences of changes in shortwave radiation at surface in summer, as large as $30 \mathrm{~W} \cdot \mathrm{m}^{-2}$ over Germany (Figure 8c). In average over Europe, aerosols explain most of the changes in solar radiation at surface in the ALADIN63 regional projection. 


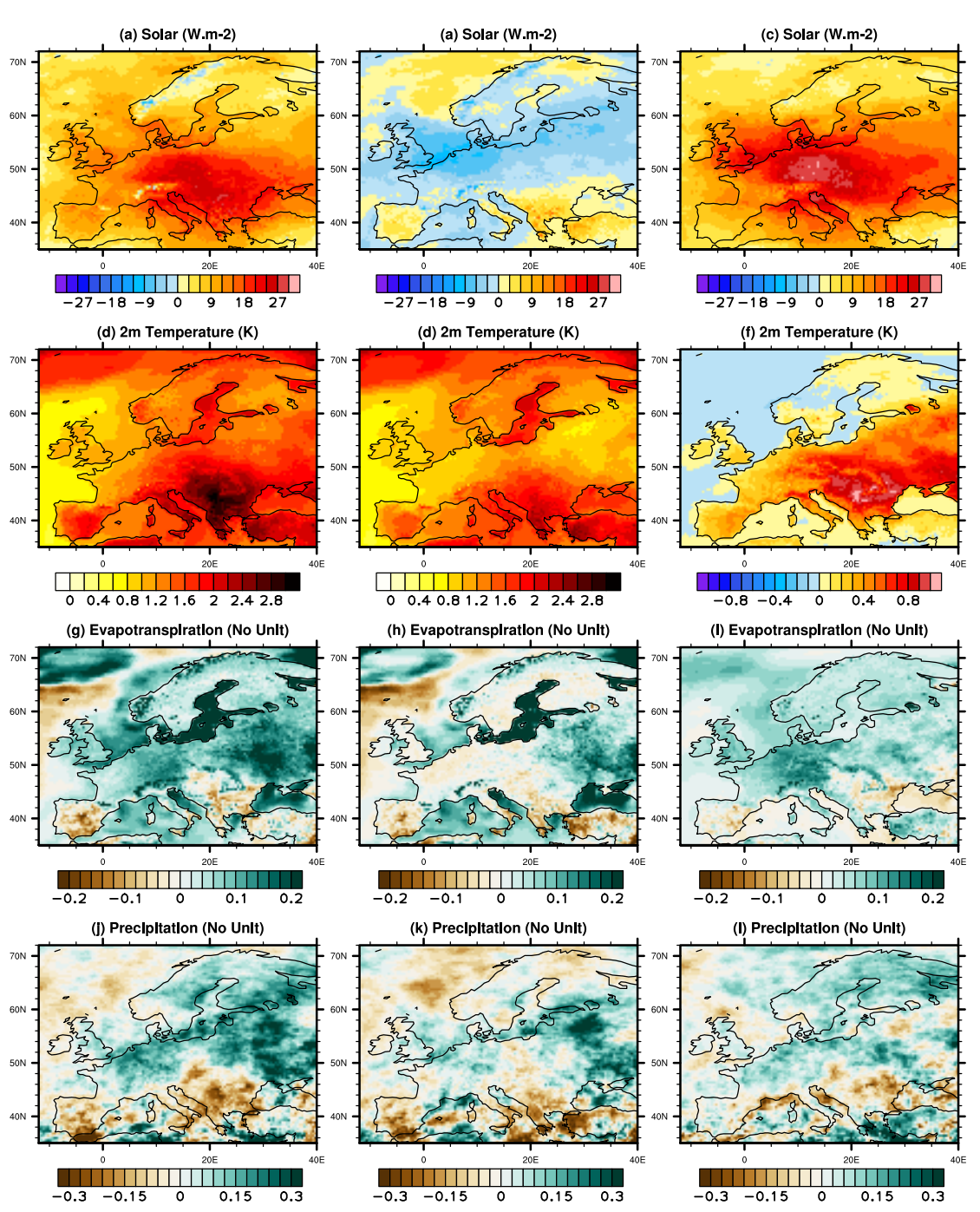

Figure 8 (a) Future summer changes (2021-2050 minus 1971-2000) in downwelling shortwave radiation at surface $\left(W \cdot m^{-2}\right)$ in ALADIN63. (b) Same as (a) with constant aerosol forcing. (c) Differences of future summmer changes in downwelling shortwave radiation at surface $\left(W \cdot m^{-2}\right)$ between the reference ALADIN63 projection and the ALADIN63 simulation with a constant aerosol forcing (i.e. (a)-(b)). See section 2. (d)-(f) same as (a)-(c) for $2 \mathrm{~m}$ air temperature (K). (g)-(i) same as (a)-(c) for evapotranspiration (no unit, relative changes are shown). (j)-(l) same as (a)-(c) for precipitation (no unit, relative changes are shown). 
Such large differences of energy available at surface lead to large differences of temperature changes, close to $1 \mathrm{~K}$ over central and eastern Europe (Figure $8 f)$. These differences are all the more notable because on the early period studied here (2021-2050) the warming in the reference simulation is only between 1 and $3 \mathrm{~K}$ over Europe (Figure 8d). In average over our domain of interest, aerosols explain roughly $0.5 \mathrm{~K}$ of the $1.8 \mathrm{~K}$ warming (i.e. roughly $30 \%$ of the warming) on 2021-2050. Note that uncertainties due to internal variability exist as these estimates are based on single members.

With time-varying aerosol forcing, a larger increase in evapotranspiration over the northern half of Europe is noted, in particular over Germany and the Benelux (Figure 8g-i). It is likely the result of the much larger increase in solar radiation at surface noted previously in the reference simulation with time-varying aerosol forcing. In the RCM used here, there is no strong limitation of evapotranspiration over Europe by soil-moisture (not shown) and therefore a larger increase of solar radiation at surface is expected to lead to a larger increase of evapotranspiration. It is all the more true since an increase of precipitation is generally simulated by this RCM over the northern half of Europe (Figure $8 \mathrm{j}$ ). This increase in precipitation is smaller in the simulation with constant aerosol forcing (Figure 8k). This difference in precipitation changes might be due to the larger increase in evapotranspiration in the simulation with evolving aerosols, through an associated larger increase in atmospheric moisture. The differences of precipitation changes due to anthropogenic aerosols are however not straightforward to interpret. On the early period studied here, internal variability plays a major role in precipitation changes (e.g. Terray and Boé 2013), and a single member, as used for the sensitivity experiment, may not be sufficient to extract a robust signal.

The sensitivity experiment described in this section clearly shows that time-varying aerosol forcing plays an important role on temperature changes through the modulation of solar radiation. It is consistent with the idea that the absence of time-varying anthropogenic aerosol forcing in most EUROCORDEX simulations explains a part of their smaller warming at surface compared to their forcing GCMs.

For precipitation, the conclusions are less clear. In the model analysed here, time-varying anthropogenic aerosol forcing tends to lead to a larger increase of precipitation rather than to a smaller one. This result is however likely dependent on the dominant control of evapotranspiration in the RCM. In a model (or on a period) in which evapotranspiration is limited by soil moisture rather by energy, the larger increase in solar radiation at surface due to timevarying aerosol forcing is expected to lead to an increase in sensible heat flux and therefore to an additional warming rather than to an increase in evapotranspiration (e.g. Boé 2016). This would tend to reduce relative humidity and precipitation. The same type of experiments with other RCMs would be necessary to test this hypothesis, and also to assess whether the strong response in shortwave radiation in the RCM studied here is a robust feature. 


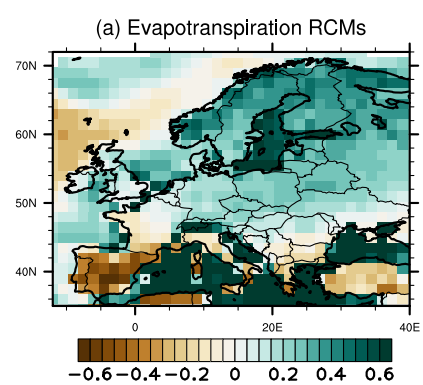

(b) Evapotranspiration GCMs

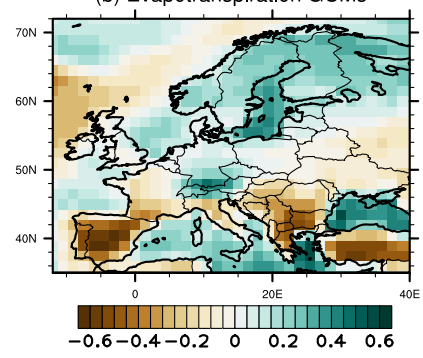

(c) Diff RCMs-GCMs

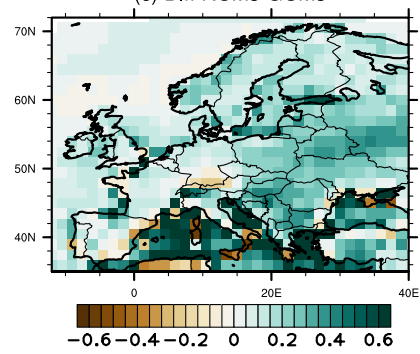

Figure 9 Ensemble mean change in evapotranspiration ( $\mathrm{mm} /$ day) in summer over Europe between 2099-2070 and 1999-1970 as (a) projected by the RCMs, as (b) projected by their driving GCMs, and (c) difference. The GCMs are weighted according to the number of RCMs they force.

\section{Role of land evapotranspiration}

As discussed in the previous section, changes in shortwave radiation may have different impacts on the surface climate depending on whether the evapotranspiration is primarily energy or water limited (e.g. Boé and Terray 2008, Boé 2016). In energy-limited regimes, changes in shortwave radiation tend to lead to an increase of evapotranspiration while in water-limited regimes an increase in sensible heat flux and surface temperature is favoured, with potential feedbacks leading to a drying of the soil and a reduction of evapotranspiration (e.g. Boé and Terray 2014).

Both the RCMs and their forcing GCMs generally simulate an increase in land evapotranspiration over the north of Europe and a decrease over southern Europe (Figure 9). Despite the much larger increase of solar radiation 
(a)

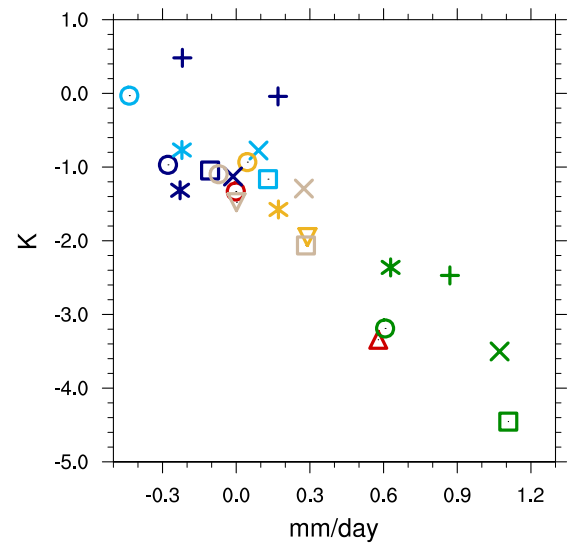

Figure 10 Difference between the RCMs and their forcing GCMs (RCMs-GCMs) in summer temperature changes $(\mathrm{K})$ versus the differences in summer evapotranspiration changes $(\mathrm{r}=-0.89)$, averaged over Europe (land points within the red box in Figure 1e). Each symbol corresponds to a particular RCM (see Table 1) and each color to a particular forcing GCM (see legend in Figure 6).

at surface in the GCMs than in the RCMs (Figure 5), the GCMs generally simulate more negative (over southern Europe) or less positive (over Scandinavia) changes in evapotranspiration than the RCMs. This is likley the sign that soil-moisture is a stronger limiting factor of evapotranspiration changes in the GCMs, likely because of the more severe precipitation changes noted previously (Figure 1), and is consistent with a larger surface warming due to less evaporative cooling. The greater differences in land evapotranspiration changes are seen over eastern Europe (Ukraine, Belarus), where the average projected change is close to $-0.2 \mathrm{~mm} /$ day for the forcing GCMs and close to $0.2 \mathrm{~mm} /$ day for the RCMs.

Unsurprisingly, a very large inter-model anti-correlation between differences in temperature changes between GCMs and RCMs and differences in evapotranspiration changes over land is noted (Figure 10, $\mathrm{r}=-0.89$ ).

The ultimate causes of the difference of evapotranspiration changes between GCMs and RCMs are not clear. Differences in precipitation changes are clearly involved, but the causes of the differences in precipitation changes remain to be understood. A first hypothesis is that the differences in precipitation changes may be related to some extent to the differences in aerosol forcing discussed previously. Indeed, the smaller warming over land due to the lack of anthropogenic aerosols variations in most RCMs could lead to smaller relative humidity changes and therefore less severe precipitation and finally evapotranspiration changes over land.

Other causes may be envisaged. Boé and Terray $(2008,2014)$ showed that in both GCMs and RCMs of previous generations, future changes in evapotranspiration over continental Europe are very dependent on the present-day 


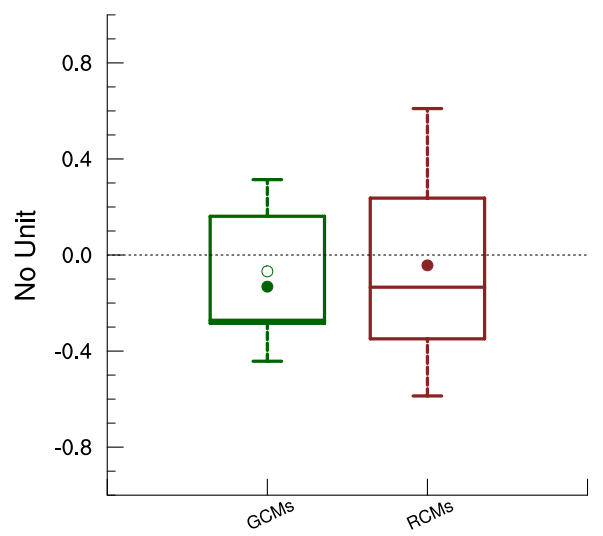

Figure 11 Intermodel distribution of present-day interannual correlations averaged over Europe (land points within the red box in Figure 1e) in summer between detrended evapotranspiration and total downwelling radiative flux at surface on the 1960-2004 period in the RCMS and their driving GCMs. See the description of the boxplots in Section 2. The symbols have the same signification than in Figure 2.

controls of evapotranspiration. Over Scandiniva, the models tend to agree on a control of evapotranspiration by the energy available at surface, and over southern Europe they tend to agree on a control of evapotranspiration by soil moisture. Over an intermediate area, the simulated controls of evapotranspiration are very uncertain. The models in which evapotranspiration is controlled by soil moisture in the present climate tend to simulate much larger decrease in evapotranspiration in the future climate (Boé and Terray 2008; 2014).

The present-day inter-annual correlations between evapotranspiration and total downwelling radiative fluxes at surface, a metric of the climatological controls of evapotranspiration (Boé and Terray 2008), is computed for the RCMs and their driving GCMs. As for the previous generation of climate models (Boé and Terray 2008, 2014), large inter-model uncertainties exist in the controls of evapotranspiration, especially in the RCMs (Figure 11). In average, the value of this metric in the RCMs and their driving GCMs is however quite similar. The present-day controls of evapotranspiration therefore cannot explain the systematic differences in evapotranspiration changes over continental Europe.

Sorland et al. (2018) have shown smaller biases for climatological temperature over land in two EURO-CORDEX RCMs compared to their multiple forcing GCMs. They make the hypothesis that it is the sign of more realistic land-atmosphere interactions in the RCMs, which could then lead to more realistic future temperature changes. It is not the case regarding the soilatmosphere interactions as characterized with our metric in the ensemble of RCMs studied here. 
Finally, it may be worth noting that the physiological forcing of $\mathrm{CO}_{2}$ is simulated by most GCMs (4 out of 6 , section 2) but not by the RCMs studied in this paper to the best of our knowledge. Under higher $\mathrm{CO}_{2}$ concentrations, the stomata do not need to be as open to absorbe $\mathrm{CO}_{2}$, which reduces the water exchanges from the plant to the atmosphere and therefore transpiration. It is increasingly clear that the reduction of evapotranspiration due the physiological $\mathrm{CO}_{2}$ forcing may be important for the future projection of evapotranspiration, as shown by Schwingshackl et al (2019) for a particular RCM, although the impact may largely differ between models (Swann et al. 2016, Lemorant et al. 2018, Skinner et al. 2018). The physiological impact of $\mathrm{CO}_{2}$ might therefore explain a part of the differences in evapotranspiration changes over land between GCMs and RCMs. Additionally, to the best of our knowledge, the RCMs analysed in this paper do not take into account land use changes contrary to most forcing GCMs. Some studies have shown that land use change may have an impact, although a limited one, on evapotranspiration changes (Quesada et al. 2017).

\section{Role of evaporation over sea}

Evapotranspiration is not only important locally because of evaporative cooling, but also through its impacts on atmospheric moisture, with potential impacts on cloud cover or precipitation. In this context, remote evaporation changes over adjacent seas may also be important, through the advection of moisture towards continents.

It is interesting to note that very large differences of evaporation changes over the Mediterranean sea (Figure 9) exist. The GCMs simulate only a moderate increase of evapotranspiration (generally close $0.2 \mathrm{~mm} /$ day) while the RCMs project a much larger increase (generally larger than $0.6 \mathrm{~mm} /$ day). It remains true excluding the IPSL-WRF331F model, which simulates a very strong and likely unrealistic increase in evapotranspiration (see Section 2).

This larger increase in RCMs than in GCMs confirms previous results reported in Sanchez-Gomez et al. (2009) and Planton et al. (2012) by comparing the CMIP3 GCM ensemble with the ENSEMBLES RCM ensemble (the RCMs being driven by CMIP3 GCMs). For the A1B scenario and the 2070-2099 period, they obtain that Mediterranean Sea evaporation increases much more in the $25-\mathrm{km}$ non-coupled RCM ensemble $(+12 \%$, about $0.4 \mathrm{~mm} /$ day $)$ than in the low-resolution coupled GCM ensemble $(+7 \%$, about $0.2 \mathrm{~mm} /$ day $)$. From their studies, it is impossible to conclude if the difference between both ensembles comes from the difference in resolution, in air-sea coupling or in the uncertainty sub-sampling (the CMIP3 ensemble being much bigger than the ENSEMBLES one).

The larger increase in evaporation over the Mediterranean sea is very likely responsible for the larger increase in atmospheric humidity at $850 \mathrm{hPa}$ in the RCMs over sea and adjacent land (Figure 12). Further inland, the differences of changes in specific humidity at $850 \mathrm{hPa}$ between GCMs and RMCs are small. 


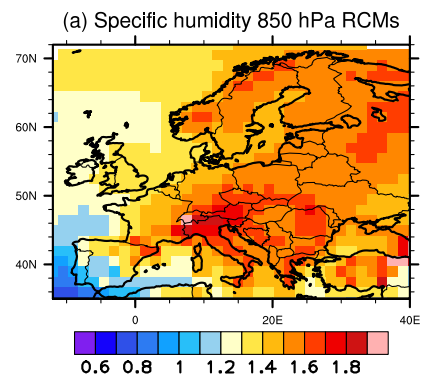

(b) Specific humidity $850 \mathrm{hPa}$ GCMs

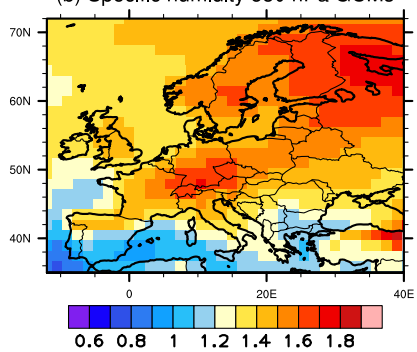

(c) Diff RCMs-GCMs

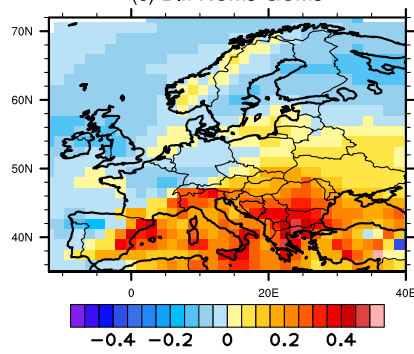

Figure 12 Ensemble mean change in specific humidity at $850 \mathrm{hPa}(\mathrm{g} / \mathrm{kg})$ in summer over Europe between 2099-2070 and 1999-1970 as (a) projected by the RCMs, as (b) projected by their driving GCMs, and (c) difference. The GCMs are weighted according to the number of RCMs they force.

A large inter-model correlation between the differences in specific humidity changes over Europe and the differences of changes in both local (over land, see previous section) and remote evapotranspiration over the Mediterranean sea are noted (Figure 13). It supports the idea that the atmosphere becomes wetter in some RCMs compared to their forcing GCMs partly because of smaller decreases or larger increases of evapotranspiration, and that the Mediterranean sea is an important source of moisture in that context.

Note that as IPSL-WRF331F simulates very large changes in evapotranspiration over the Mediterranean sea compared to the other RCMs (close to 3.15 $\mathrm{mm} /$ day, it does not appear on the scatter plot in Figure 13a. Note also that the differences of both evapotranspiration and specific humidity changes are especially large between HadGEM2-ES and the RCMs forced by HadGEM2- 


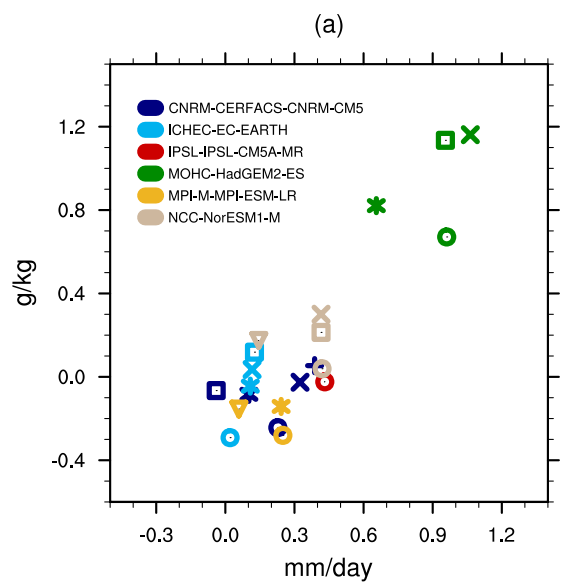

(b)

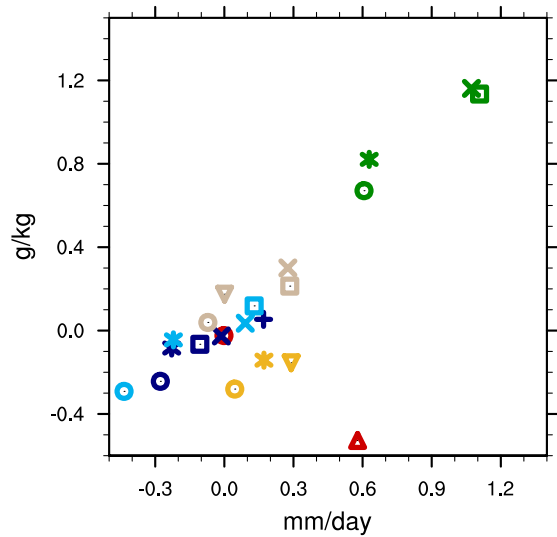

Figure 13 Difference of changes in specific humidity at $850 \mathrm{hPa}(\mathrm{g} / \mathrm{kg})$ versus difference of changes in evapotranspiration (mm/day) between the RCMs and their driving GCMs (RCMs-GCMs) in summer. For (a) and (b) the changes in specific humidity over Europe (land points within the red box in Figure 1e) are considered. For (a) the changes in evapotranspiration over the Mediterranean Sea are considered. For (b) the local changes in evapotranspiration over Europe are considered. The differences between 2070-2099 and 1970-1999 are calculated. Each symbol corresponds to a particular RCM (see Table 1) and each color to a particular forcing GCM.

ES. HadGEM2-ES is the driving GCM with the largest increase in temperature and the smallest increase in specific humidity at $850 \mathrm{hPa}$, both over the Mediterranean sea and continental Europe (not shown). HadGEM2-ES also simulates the largest decrease in evapotranspiration over Europe. The increase in evaporation over the Mediterranean sea in HadGEM2-ES is rather small compared to the other GCMs (not shown).

With regard to summer climate changes, changes in relative humidity are also very important (e.g. Boé and Terray 2014). For example, the lower the relative humidity is, the harder it is to reach saturation and therefore poten- 


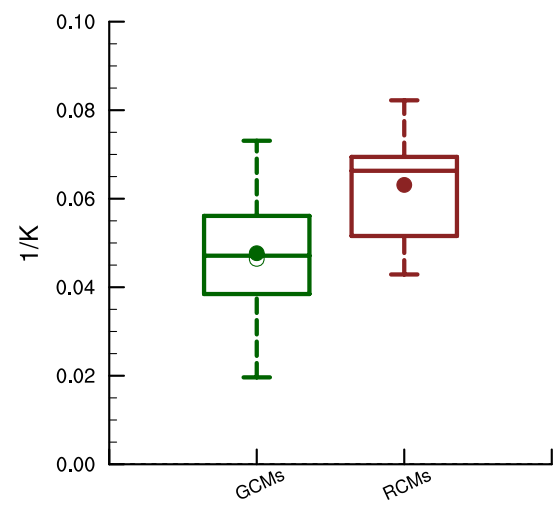

(b)

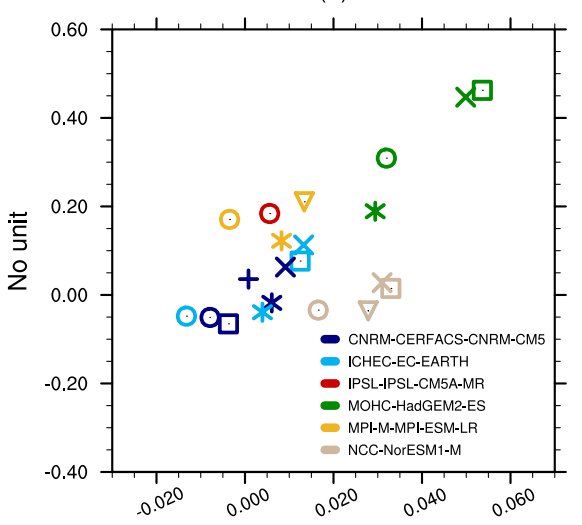

Figure 14 (a) Intermodel distribution of the ratio of relative specific humidity change to temperature change at $850 \mathrm{hPa}(1 / \mathrm{K})$ averaged over Europe in summer (land points within the red box in Figure 1e) in the RCMs and their driving GCMs. (b) Differences in relative changes in summer precipitation (no unit) between the RCMs and the GCMs as a function of the difference in the ratio of relative specific humidity change to temperature change at $850 \mathrm{hPa}(1 / \mathrm{K})$ over Europe in summer. The differences between 2070-2099 and 1970-1999 are calculated. Each symbol corresponds to a particular RCM (see Table 1) and each color to a particular forcing GCMs.

tially to form clouds and/or precipitation. The changes in specific humidity are generally rather close between the RCMs and their forcing GCMs over land away from the sea (Figure 12) but the warming is largely smaller in the RCMs (Figure 1). As a result, the ratio between the change in specific humidity and the change in temperature over land is generally smaller in the GCMs than in the RCMs (Figure 14a). The larger differences are seen over the Balkans (not shown), where the GCMs warm much more than the RCMs (Figure 1) and where the specific humidity increases much more in the RCMs because of the larger increase in evaporation over the Mediterranean sea (Figure 9). 
Following the Clausius Clapeyron relation, the specific humidity at saturation increases approximately by $7 \% \cdot K^{-1}$ (e.g. Held and Soden 2006). Therefore a ratio of specific humidity change to temperature change close to $7 \% \cdot K^{-1}$ is equivalent to no change in relative humidity while a much smaller ratio indicates that a large decrease in relative humidity occurs. The RCMs therefore generally show small changes in relative humidity while the forcing GCMs show decreases and sometimes large decreases (Figure 14a).

The importance of the differences in relative humidity changes is highlighted by the link found over land between the differences in precipitation changes and the differences of the ratio of the change in specific humidity to the change in temperature at $850 \mathrm{hPa}$ (Figure 14b).

Given the seemingly importance for climate changes over Europe of differences in evaporation changes between RCMs and GCMs over the Mediterranean Sea, it would be important to understand their causes. First, some issues with the remapping of GCM SSTs to force the RCMs have been noted for some models (https ://euro-cordex.net/078730/index.php.en). They may explain larger evapotranspiration changes locally over sea near the coast in some RCMs. However, large differences are also seen away from the coasts (Figure 9). These large differences are somewhat surprising. Indeed, for the calculation of evaporation over sea, the atmosphere component in a RCM and its forcing GCM use the same SST by construction, which plays an important role on evapotranspiration, through its impact on specific humidity at saturation at the surface. Differences in the parameterization of evaporation, e.g. the exchange coefficients, may exist between the RCMs and the GCMs but there is no reason for the resulting differences in evaporation changes to be systematic (e.g. Figure 13) for all the RCMs / GCMs pairs.

Some differences in surface wind speed changes over sea in summer are noted between the RCMs and GCMs for which this variable is available, with generally somewhat larger decreases in the GCMs (a few percent, not shown). These differences are however likely insufficient to explain alone the large differences in evapotranspiration changes. Why such differences in wind speed changes exist in the first place is not clear. The representation of wind near the coast where the influence of orography can be felt is likely improved in the RCMs (Herrmann et al. 2011), but this impact is weaker far from the coast. Additionally, Herrmann et al. (2011) have shown that the coupling with the ocean has only a very weak mean impact on wind speed.

The impact of the coupled framework of the GCMs versus the forced framework of the RCMs should be considered more generally. Short-term negative feedbacks exist in a coupled framework but not in a forced framework. For example, very warm SSTs may result in strong evaporation and convection, with the development of clouds, which results in a reduction of shortwave radiation at surface and, in a coupled framework in a reduction of SSTs. Such a negative feedback does not exist in a forced framework. Unfortunately, it is not possible to go further without twin regional simulations based on the exact same RCM, with and without coupling over the Mediterranean sea. Such experiments have been done by Somot et al. (2008). Unfortunately, the eva- 
potranspiration changes are not shown in the latter study but it shows that the coupling over the Mediterranean sea leads to a larger decrease of precipitation over the south of eastern Europe, which could be consistent with the mechanisms described previously. Concerning evaporation over the Mediterranean Sea, Planton et al. (2012) compared an Atmosphere-only RCM ensemble (ENSEMBLES project, Sanchez-Gomez et al. 2009) with a coupled Atmosphere-Ocean RCM model ensemble (CIRCE project, Dubois et al. 2012) for the A1B scenario and the 2020-2049 period. They obtain a larger increase with the non-coupled models $(+4 \%$, about $+0.2 \mathrm{~mm} /$ day $)$ than with the coupled models $(+3 \%,+0.1 \mathrm{~mm} /$ day $)$. Even if both ensembles are not directly comparable (the ensemble size is larger in ENSEMBLES than in CIRCE) and if the temporal horizon is different from the one we study, those results are consistent with our assumption about the ocean-atmosphere coupling effect in RCMs.

The differences of evapotranspiration changes over the Mediterranean sea, together with the differences in evapotranspiration changes over land between the RCMs and their driving GCMs discussed in the previous section, likely modulate the differential evolution of specific and relative humidity over land in the RCMs, with a possible impact on precipitation and cloud cover, and likely explain a part of the differences in surface warming. Local feedbacks may exist in that context as changes in cloud cover (through the modulation of shortwave radiation) and precipitation (through a modulation of evapotranspiration via soil moisture) may impact in return surface temperature, which itself directly impacts relative humidity (Vogel et al. 2018).

Note that the differences of evapotranspiration changes over land discussed in the previous section could be driven by evaporation changes over the Mediterranean sea. As discussed, larger evapotranspiration changes over the Mediterranean sea may result in smaller decreases in relative humidity and then precipitation over land. These changes in precipitation would directly impact continental evapotranspiration.

Previous studies (e.g. Rowell et al. 2006) have highlighted the potential impact of the increased land-sea temperature contrast in the future climate. It leads to a larger increase in atmospheric water-holding capacity over land than over sea, so that air advected from the sea over the continent experiences a larger decrease in relative humidity in the future climate, with a potential associated reduction of clouds, precipitation and evapotranspiration. In the RCM simulations without time-varying aerosols, an inconsistency may exist between land and sea warming. The absence of aerosol variations leads to a smaller warming over land but it is not the case over sea as SST from the GCMs, which include variations in aerosols, are imposed. The absence of time-varying aerosols in a forced ocean framework therefore likely reduces the increase of the land-sea warming contrast in the future climate, with the potential consequences noted above. 


\section{Conclusion}

In this study, we have shown that large differences exist in summer climate changes over Europe as projected by the $12 \mathrm{~km}$ EURO-CORDEX RCMs and their forcing CMIP5 GCMs, and more generally the full ensemble of CMIP5 GCMs. As an ensemble, the RCMs project over a large area of Europe at the end of the 21st century a summer warming 1.5-2 K colder and a decrease of precipitation roughly 4 time smaller ( $-20 \%$ versus $-5 \%)$ than their driving GCMs.

Such inconsistencies between RCMs and GCMs projections, at large scales, are problematic. Such large differences may have profound consequences in terms of impacts and adaptation. It is therefore crucial to understand whether these differences may be related to an added value of higher resolution or to other factors, and therefore in the end whether more confidence should be given to current RCMs or GCMs results.

Our strategy has been to study in details the mechanisms responsible for the differences in precipitation and temperature changes and then to assess whether or not structural differences between GCM and RCM (e.g. differences of forcings, resolution, coupling etc.) may play on these mechanisms.

The forcing GCMs generally simulate a much larger increase in shortwave radiation at surface than the RCMs, as already noted by Bartok et al (2017) and Gutierrez-Escribano et al. (in review). Differences in changes of cloud cover alone cannot explain the totality of these differences and we argue that anthropogenic aerosols play a very important role in this context. The absence of time-evolving anthropogenic aerosol forcing in most RCMs (17 out of the 24 simulations) indeed leads to a smaller increase of downwelling shortwave radiation at surface in the RCMs than in their driving GCMs. It is clear based on our results that this mechanism plays an important role in the differences of projected changes between RCMs and GCMs, as confirmed by a dedicated sensitivity experiment, at least for solar radiation and temperature.

The future evolution of anthropogenic aerosols is uncertain, and the RCPs scenarios, as used in this study, do not necessarily capture the full range of possible evolutions (Bellucci et al. 2015; van Vuuren 2011). Given the great importance of anthropogenic aerosols for summer climate changes over Europe shown in this study or previous works (e.g. Boé 2016) more work is clearly needed to better explore the uncertainties associated with the future evolution of anthropogenic aerosols. Even if uncertainties exist, it is clear that until today the evolution of aerosols is much better captured by the historical + RCP (e.g. Klimont 2013) evolution of GCMs and ALADIN / RACMO, than by the constant aerosols concentrations of most EURO-CORDEX RCMs.

Note also that the absence of variation of $\mathrm{CO}_{2}$ in two RCMs (5 projections over 24) is also expected to have an impact on surface temperature changes (Jerez et al., 2018) and likely precipitation changes.

The RCMs also simulate a much larger increase in evaporation over the Mediterranean sea that likely leads to smaller relative humidity changes over the continent, which could then favor a smaller decrease in cloud cover, preci- 
pitation and finally evapotranspiration, and a smaller increase in temperature. Causes of these differences in evaporation changes over sea are unclear, but it would be worth investigating the role of missing ocean-atmosphere coupling in RCMs. Larger decreases / smaller increases of evapotranspiration over Europe in GCMs are also projected over the continent, which is consistent with the larger warming and greater precipitation decrease projected by the GCMs. It is difficult to assess whether these differential evapotranspiration changes over land are simply the results of the mechanisms described above or whether specific structural causes may exist. For example, the absence of the physiological effect of $\mathrm{CO}_{2}$ in RCMs that is taken into account by the majority of the forcing GCMs may play a role (e.g. Schwingshackl et al. 2019).

Several potential explanations exist to the differences of evapotranspiration changes between EURO-CORDEX RCMs and their forcing CMIP5 GCMs. For the time being, we think that there is no strong reason to suppose that the evapotranspiration changes in the RCMs are more realistic than the ones from their driving GCMs.

Dedicated numerical experiments would be necessary to go further, in particular to better evaluate the impact of differential forcings and of oceanatmosphere coupling. Some of these simulations are ongoing, within the MEDCORDEX project for the impact of coupling (CORDEX FPS-airsea), and for the impact of aerosols (CORDEX FPS-aerosol), following the same protocol as used in the sensitivity experiments described in section 4.2.

Our study highlights that greater care should be given to the characterization and understanding of the potential discrepancies between RCMs and GCMs at large scales. We show that the EURO-CORDEX projections do not cover at large scales the full range of changes projected by the CMIP5 GCMs, with in particular no regional projection showing the strong summer warming and drying seen in a substantial number of GCMs (Figure 2). Given the caveats associated with regional climate projections discussed in this study, there is currently no rationale to discard the more severe changes projected by GCMs. We therefore urge climate change impacts studies to not simply focus on current EURO-CORDEX regional projections but to also consider the results obtained with GCMs, in order to avoid a potential large underestimation of the uncertainties in projected impacts.

Acknowledgements We acknowledge the World Climate Research Programme's Working Group on Regional Climate, and the Working Group on Coupled Modelling, former coordinating body of CORDEX and responsible panel for CMIP5. We also thank the climate modelling groups (listed in Table 1 of this paper) for producing and making available their model output. We also acknowledge the Earth System Grid Federation infrastructure an international effort led by the U.S. Department of Energy's Program for Climate Model Diagnosis and Intercomparison, the European Network for Earth System Modelling and other partners in the Global Organisation for Earth System Science Portals (GO-ESSP). ETH Zurich, Institute for Atmospheric and Climate Science, is acknowledged for providing and maintaining the Global Energy Balance Archive Data. The figures have been produced using the NCAR Command Language (NCAR Command Language (Version 6.6.2) [Software]. (2019). Boulder, Colorado : UCAR/NCAR/CISL/TDD. http ://dx.doi.org/10.5065/D6WD3XH5). This study contributes to the CORDEX FPS-aerosol, a Flagship Pilot Study proposed by Med- 
CORDEX (www.medcordex.eu). S. Somot has been partly supported by the EUCP project. EUCP is financed by the European Commission through the Horizon 2020 Programme for Research and Innovation, Grant Agreement 776613.

\section{Références}

1. Akhtar N, Brauch J, Ahrens B (2018) Climate modeling over the Mediterranean Sea : impact of resolution and ocean coupling. Clim Dyn 51 :933-948. doi : 10.1007/s00382-0173570-8

2. Bartók B, Wild M, Folini D, et al (2017) Projected changes in surface solar radiation in CMIP5 global climate models and in EURO-CORDEX regional climate models for Europe. Clim Dyn 49 :2665-2683. doi : 10.1007/s00382-016-3471-2

3. Boé J (2016) Modulation of the summer hydrological cycle evolution over western Europe by anthropogenic aerosols and soil-atmosphere interactions. Geophys Res Lett. doi : 10.1002/2016GL069394

4. Boé J, Terray L (2008) Uncertainties in summer evapotranspiration changes over Europe and implications for regional climate change. Geophys Res Lett 35 :1-5. doi : 10.1029/2007GL032417

5. Boé J, Terray L (2014) Land-sea contrast, soil-atmosphere and cloud-temperature interactions : Interplays and roles in future summer European climate change. Clim Dyn 42 :683-699. doi : 10.1007/s00382-013-1868-8

6. Bellucci A, Haarsma R, Bellouin N, Booth B, Cagnazzo C et al. ( 2015), Advancements in decadal climate predictability : The role of nonoceanic drivers, Rev Geophys 53, 165202. doi :10.1002/2014RG000473.

7. Brogli R, Kröner N, Sørland SL, et al (2019) The role of hadley circulation and lapse-rate changes for the future European summer climate. J Clim. doi : 10.1175/JCLI-D-18-0431.1

8. Schwingshackl C, Davin EL, Hirschi M, Sørland SL, Wartenburger R, Seneviratne SI (2019) Environ. Res. Lett. 14114019

9. Colin J, DéQué M, Radu R, Somot S (2010) Sensitivity study of heavy precipitation in Limited Area Model climate simulations : Influence of the size of the domain and the use of the spectral nudging technique. Tellus, Ser A Dyn Meteorol Oceanogr. doi : 10.1111/j.1600-0870.2010.00467.x

10. Collins M, Knutti R, Arblaster J, et al (2013) Long-term Climate Change : Projections, Commitments and Irreversibility. In : Stocker TF, Qin D, Plattner G-K, et al. (eds) Climate Change 2013 : The Physical Science Basis. Contribution of Working Group I to the Fifth Assessment Report of the Intergovernmental Panel on Climate Change. Cambridge University Press, Cambridge, United Kingdom and New York, NY, USA, pp 1029-1136

11. Déqué M, Somot S (2008) Extreme precipitation and high resolution with Aladin. Idöjaras Quaterly J Hungarian Meteorol Serv 112 :179-190

12. Déqué M, Somot S, Sanchez-Gomez E, et al (2012) The spread amongst ENSEMBLES regional scenarios : Regional climate models, driving general circulation models and interannual variability. Clim Dyn 38 :951-964. doi : 10.1007/s00382-011-1053-x

13. Dubois C, Somot S, Calmanti S, Carillo A, Déqué M, Dell'Aquilla A, Elizalde-Arellano A, Gualdi S, Jacob D, Lheveder B, Li L, Oddo P, Sannino G, Scoccimarro E, Sevault F (2012) Future projections of the surface heat and water budgets of the Mediterranean sea in an ensemble of coupled atmosphere-ocean regional climate models, Clim Dyn 39 (7-8) :1859-1884. DOI 10.1007/s00382-011-1261-4.

14. Fantini A, Raffaele F, Torma C, et al (2018) Assessment of multiple daily precipitation statistics in ERA-Interim driven Med-CORDEX and EURO-CORDEX experiments against high resolution observations. Clim Dyn 51 :877-900. doi : 10.1007/s00382-0163453-4 
15. Fernández J, Frías MD, Cabos WD, et al (2018) Consistency of climate change projections from multiple global and regional model intercomparison projects. Clim Dyn 0 :1-18. doi : 10.1007/s00382-018-4181-8

16. Fischer EM, Schär C (2010) Consistent geographical patterns of changes in high-impact European heatwaves. Nat Geosci. doi : 10.1038/ngeo866

17. Forster P, et al (2007), Changes in atmospheric constituents and radiative forcing, in Climate Change 2007 : The Physical Science Basis : Contribution of Working Group I to the Fourth Assessment Report of the Intergovernmental Panel on Climate Change, edited by S. Solomon et al., pp. 129-234, Cambridge Univ. Press, New York.

18. Gaertner MÁ, González-Alemán JJ, Romera R, et al (2018) Simulation of medicanes over the Mediterranean Sea in a regional climate model ensemble : impact of ocean-atmosphere coupling and increased resolution. Clim Dyn. doi : 10.1007/s00382016-3456-1

19. Gilgen H, Wild M, Ohmura A (1998) Means and trends of shortwave irradiance at the surface estimated from global energy balance archive data, J Clim, 11 :2042-2061.

20. Giorgi F, Gutowski WJ (2015) Regional Dynamical Downscaling and the CORDEX Initiative. Annu Rev Environ Resour 40 :467-490. doi : 10.1146/annurev-environ-102014021217 Giorgi F, Torma C, Coppola E, et al (2016) Enhanced summer convective rainfall at Alpine high elevations in response to climate warming. Nat Geosci 9 :584-589. doi : $10.1038 /$ ngeo2761

21. Gutierrez-Escribano C, Somot S, Nabat P, Mallet M, Corre L, Van Meijgaard E, Gartner MA, Perpinan O (2019) Future evolution of surface solar radiation and photovoltaic potential in Europe : investigating the role of aerosols (in rev. for ERL)

22. He J, Soden BJ (2017) A re-examination of the projected subtropical precipitation decline. Nat Clim Chang 7 :53-57. doi : $10.1038 /$ nclimate3157

23. Held IMIM, Soden BJBJ (2006) Robust responses of the hydrological cycle to global warming. J Clim 19 :5686-5699. doi : 10.1175/JCLI3990.1

24. Herrmann M, Somot S, Calmanti S, et al (2011) Representation of spatial and temporal variability of daily wind speed and of intense wind events over the Mediterranean Sea using dynamical downscaling : impact of the regional climate model configuration. Nat Hazards Earth Syst Sci 11 :1983-2001. doi : 10.5194/nhess-11-1983-2011

25. Jacob D, Petersen J, Eggert B, et al (2014) EURO-CORDEX : new high-resolution climate change projections for European impact research. Reg Environ Chang 14 :563-578. doi : 10.1007/s10113-013-0499-2

26. Jerez S, López-Romero JM, Turco M, et al (2018) Impact of evolving greenhouse gas forcing on the warming signal in regional climate model experiments. Nat Commun $9: 1304$. doi : 10.1038/s41467-018-03527-y

27. Klimont Z, Smith SJ, Cofala J (2013) The last decade of global anthropogenic sulfur dioxide : 2000-2011 emissions, Environ Res Lett, 8(1) doi :10.1088/1748-9326/8/1/014003.

28. Kröner N, Kotlarski S, Fischer E, et al (2017) Separating climate change signals into thermodynamic, lapse-rate and circulation effects : theory and application to the European summer climate. Clim Dyn 48 :3425-3440. doi : 10.1007/s00382-016-3276-3

29. Leduc M, Laprise R (2009) Regional climate model sensitivity to domain size. Clim Dyn. doi : 10.1007/s00382-008-0400-z

30. Lemordant L, Gentine P, Swann AS, et al (2018) Critical impact of vegetation physiology on the continental hydrologic cycle in response to increasing CO 2. Proc Natl Acad Sci 115 :4093-4098. doi : 10.1073/pnas.1720712115

31. McSweeney CF, Jones RG, Lee RW, Rowell DP (2015) Selecting CMIP5 GCMs for downscaling over multiple regions. Clim Dyn 44 :3237-3260. doi : 10.1007/s00382-0142418-8 Monerie PA, Sanchez-Gomez E, Boé J (2016) On the range of future Sahel precipitation projections and the selection of a sub-sample of CMIP5 models for impact studies. Clim Dyn 1-20. doi : 10.1007/s00382-016-3236-y 
32. Myhre, G., D. Shindell, F.-M. Bréon, W. Collins, J. Fuglestvedt, J. Huang, D. Koch, J.-F. Lamarque, D. Lee, B. Mendoza, T. Nakajima, A. Robock, G. Stephens, T. Takemura and H. Zhang, 2013 : Anthropogenic and Natural Radiative Forcing. In : Climate Change 2013 : The Physical Science Basis. Contribution of Working Group I to the Fifth Assessment Report of the Intergovernmental Panel on Climate Change [Stocker, T.F., D. Qin, G.-K. Plattner, M. Tignor, S.K. Allen, J. Boschung, A. Nauels, Y. Xia, V. Bex and P.M. Midgley (eds.)]. Cambridge University Press, Cambridge, United Kingdom and New York, NY, USA.

33. Nabat P, Somot S, Mallet M, et al (2015) Direct and semi-direct aerosol radiative effect on the Mediterranean climate variability using a coupled regional climate system model. Clim Dyn 44 :1127-1155. doi : 10.1007/s00382-014-2205-6

34. Nabat P, Somot S, Mallet M, et al (2014) Contribution of anthropogenic sulfate aerosols to the changing Euro-Mediterranean climate since 1980. Geophys Res Lett. doi : 10.1002/2014GL060798

35. Orlowsky B, Seneviratne SI (2013) Elusive drought : Uncertainty in observed trends and short-and long-term CMIP5 projections. Hydrol Earth Syst Sci. doi : 10.5194/hess17-1765-2013

36. Pinto I, Jack C, Hewitson B (2018) Process-based model evaluation and projections over southern Africa from Coordinated Regional Climate Downscaling Experiment and Coupled Model Intercomparison Project Phase 5 models. Int J Climatol. doi : 10.1002/joc.5666

37. Prein AF, Gobiet A, Truhetz H, et al (2016) Precipitation in the EURO-CORDEX 0.11 and 0.44 simulations : high resolution, high benefits? Clim Dyn 46 :383-412. doi : 10.1007/s00382-015-2589-y

38. Planton S, Lionello P, Artale V, Aznar R, Carillo A, Colin J, Congedi L, Dubois C, Elizalde Arellano A, Gualdi S, Hertig E, Jordà Sanchez G, Li L, Jucundus J, Piani C, Ruti P, Sanchez-Gomez E, Sannino G, Sevault F, Somot S (2012) The climate of the Mediterranean region in future climate projections (chapter 8) In : Mediterranean Climate Variability, Ed. Lionello, P, Elsevier, pp. 449-502

39. Quesada B, Arneth A, de Noblet-Ducoudré N (2017) Atmospheric, radiative, and hydrologic effects of future land use and land cover changes : A global and multimodel climate picture. J Geophys Res Atmos 122 :5113-5131. doi : 10.1002/2016JD025448

40. Rajczak J, Schär C (2017) Projections of Future Precipitation Extremes Over Europe : A Multimodel Assessment of Climate Simulations. J Geophys Res Atmos 122 :10,77310,800. doi : 10.1002/2017JD027176

41. Rowell DP, Jones RG (2006) Causes and uncertainty of future summer drying over Europe. Clim Dyn 27 :281-299. doi : 10.1007/s00382-006-0125-9

42. Ruosteenoja K, Markkanen T, Venäläinen A, et al (2018) Seasonal soil moisture and drought occurrence in Europe in CMIP5 projections for the 21st century. Clim Dyn 50 :1177-1192. doi : 10.1007/s00382-017-3671-4

43. Saini R, Wang G, Yu M, Kim J (2015) Comparison of RCM and GCM projections of boreal summer precipitation over Africa. J Geophys Res. doi : 10.1002/2014JD022599

44. Schoetter R, Cattiaux J, Douville H (2015) Changes of western European heat wave characteristics projected by the CMIP5 ensemble. Clim Dyn. doi : 10.1007/s00382-0142434-8

45. Skinner CB, Poulsen CJ, Mankin JS (2018) Amplification of heat extremes by plant CO2physiological forcing. Nat Commun 9 :1-11. doi : 10.1038/s41467-018-03472-w

46. Somot S, Sevault F, Déqué M, Crépon M (2008) 21st century climate change scenario for the Mediterranean using a coupled atmosphere-ocean regional climate model. Glob Planet Change 63 :112-126. doi : 10.1016/j.gloplacha.2007.10.003

47. Sanchez-Gomez E, Somot S, Mariotti A (2009) Future changes in the Mediterranean water budget projected by an ensemble of Regional Climate Models Geophys. Res. Lett., 36 (21), doi :10.1029/2009GL040120

48. Sørland SL, Schär C, Lüthi D, Kjellström E (2018) Bias patterns and climate change signals in GCM-RCM model chains. Environ Res Lett 13 :074017. doi : 10.1088/1748$9326 / \operatorname{aacc} 77$ 
49. Swann ALS, Hoffman FM, Koven CD, Randerson JT (2016) Plant responses to increasing CO 2 reduce estimates of climate impacts on drought severity. Proc Natl Acad Sci 113 :10019-10024. doi : 10.1073/pnas.1604581113

50. Szopa S, Cozic A, Shulz M, Balkanski Y, Hauglustaine D (2032) Aerosol and ozone changes as forcing for climate evolution between 1850 and 2100. Clim Dyn 40 : 2223. https ://doi.org/10.1007/s00382-012-1408-y

51. Taylor KE, Stouffer RJ, Meehl GA (2012) An Overview of CMIP5 and the Experiment Design. Bull Am Meteorol Soc 93 :485-498. doi : 10.1175/BAMS-D-11-00094.1

52. Terray L, Boé J (2013) Quantifying 21st-century France climate change and related uncertainties. Comptes Rendus - Geosci 345 :136-149. doi : 10.1016/j.crte.2013.02.003

53. van Vuuren DP et al. (2011) The representative concentration pathways : An overview, Clim Change 109(1-2) :5-31.

54. Vogel MM, Zscheischler J, Seneviratne SI (2018) Varying soil moisture-atmosphere feedbacks explain divergent temperature extremes and precipitation projections in Central Europe. Earth Syst Dyn Discuss 1-29. doi : 10.5194/esd-2018-24

55. Wild M (2009) Global dimming and brightening : A review. J Geophys Res 114 :D00D16. doi : 10.1029/2008JD011470

56. Wild M, Ohmura A, Schär C, Müller G, Folini D, Schwarz M, Hakuba MZ, SanchezLorenzo A (2017) The Global Energy Balance Archive (GEBA) version 2017 : a database for worldwide measured surface energy fluxes, Earth Syst. Sci. Data, 9, 601-613, https ://doi.org/10.5194/essd-9-601-2017, 2017. 